Journal of Sustainable Agricultural Sciences
http://jsas.journals.ekb.eg/

استهدف البحث بصفة رئيسية التعرف علي طبيعة أنشطة التو اصل الإرشادي التي بقوم بها العاملين الإرشاديين

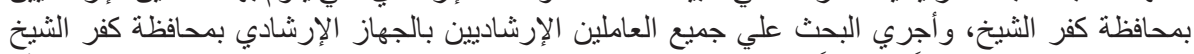

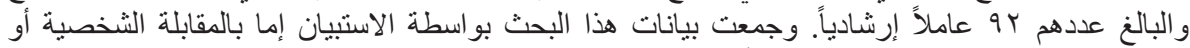

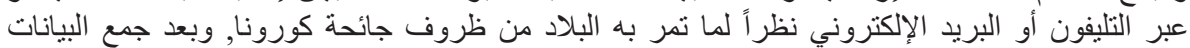

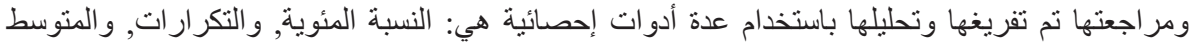

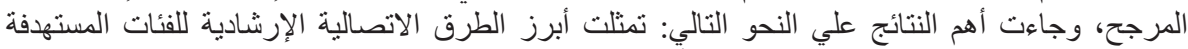

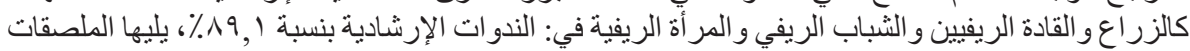

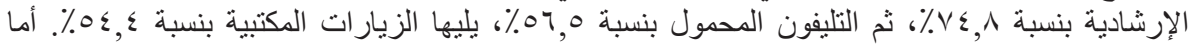

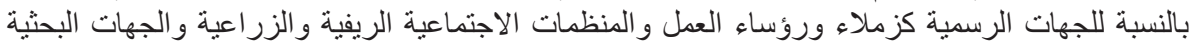

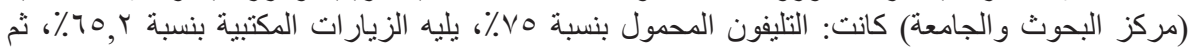

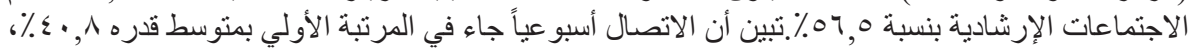

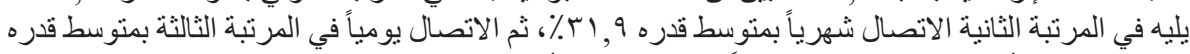

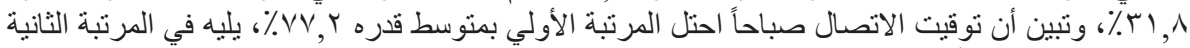

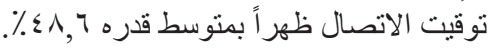

الكلمات المفتاحية: الزراع، الأنثطة الاتصالية، القادة الريفيين، المرأة الريفية، المنظمات، الثباب الريفي، الطرق الاتصالية، العاملين الإرشاديين.

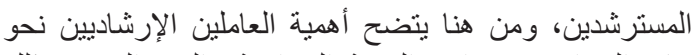

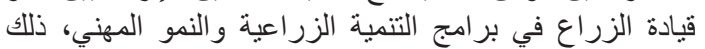

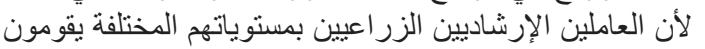

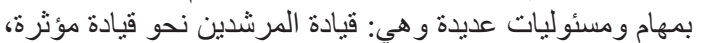

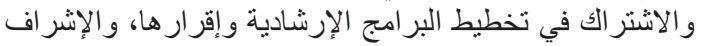

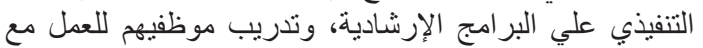

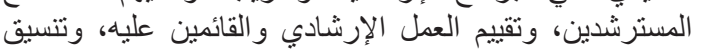

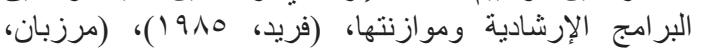

هذا وتتأثر عملية نقل التوصيات والثقتيات الزراعية

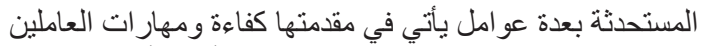
في الإرشاد الزراعي والَّنين يؤدون دوراً هاماًاً في إيصال

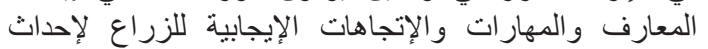

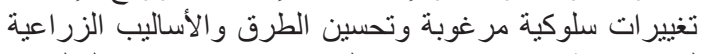

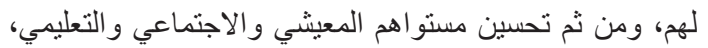

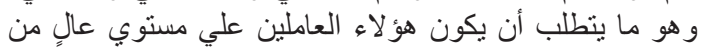

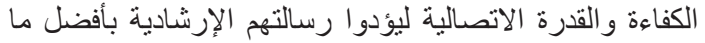

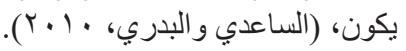
حيث يعمل الإرشاد الزراعي في مجالاته المتنوعة مع لئاع
المقدمة ومشكلة البحث

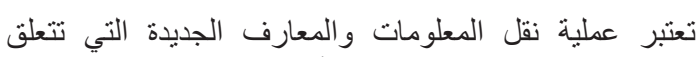

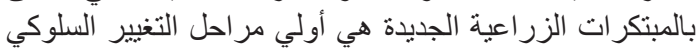

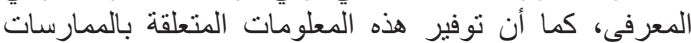

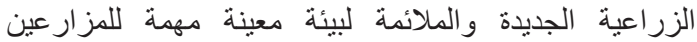
و المجتمع الريفي لتحديث معارفهم ومهار اتهم الزر اعية، (سلام

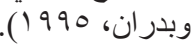

حيث أن أهم مر احل تنمية العنصر البشري تكون من خلال

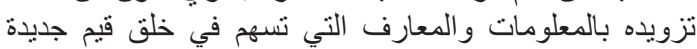

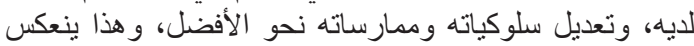

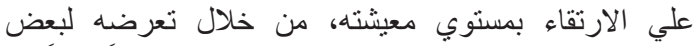

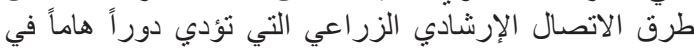

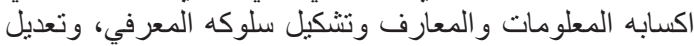

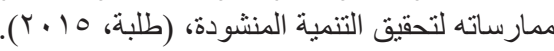

ويتم ذلك من خلال قيام التنظيم الإرشادي بحسن استثمار كافة

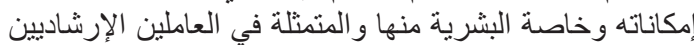

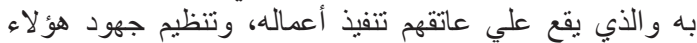
العاملين علي المستويات المختلفة لتوصيل الخدمة الإرشادية إلي 
الإرشادي؟، وما شكل اتصال العاملين الإرشاديين بالفئات المستهدفة من عملية الاتصال الإرشادي؟ أنمال

أهداف البحث

يستهدف البحث بصفة رئيسية التعرف علي طبيعة الأنشطة

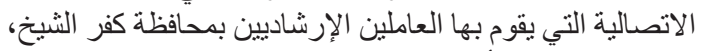
من خلال تحقيق الأهداف الفرعية التالية الألية:

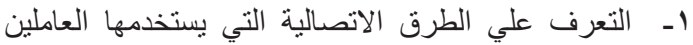

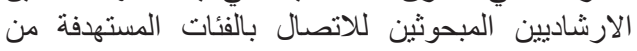

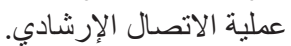

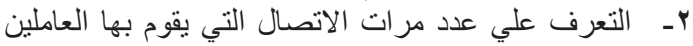

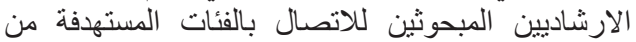
عملية الاتصال الإرشادي.

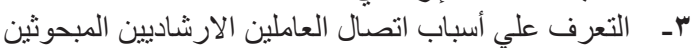

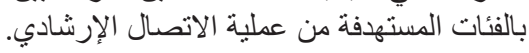

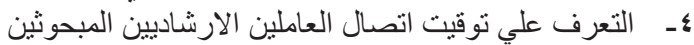

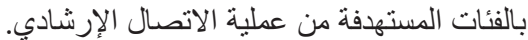

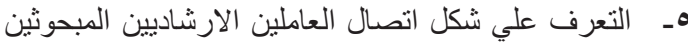

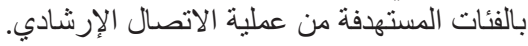

\section{الاستعر اض المرجعى}

أو لاً: مفهوم الاتصال Communication Concept:

يعرف العادلي (T/ I I ) الاتصال بأنه: "العملية التي يسنطيع

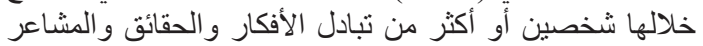

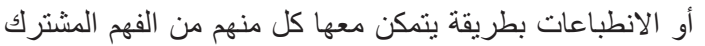

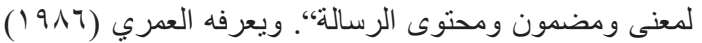

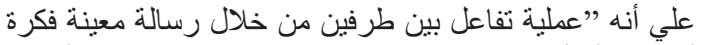

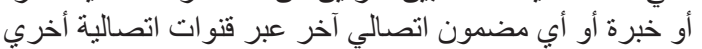

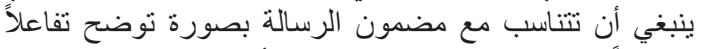

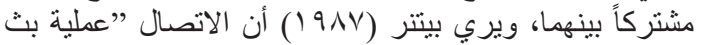

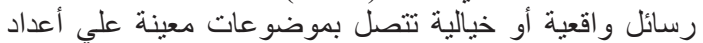
كبيرة من الناس مختلفين فيما بينهم في النواتية احي الاقتصادية

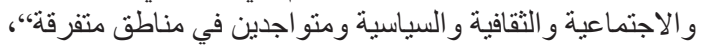

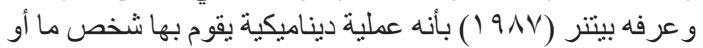

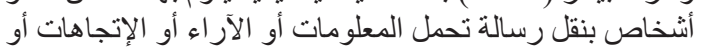

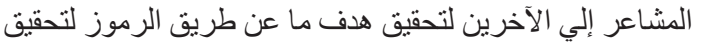

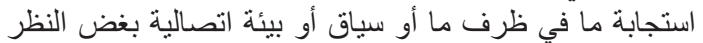
عن ما قد يعترضها من تشويش"،

ويشير عبد المقصود (911 (1) إلى أن الاتصال هو: "العملية

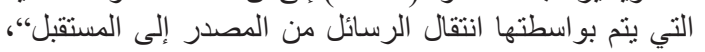

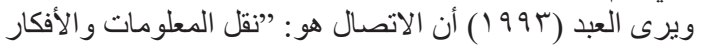

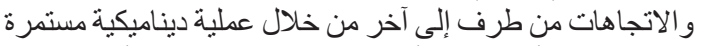

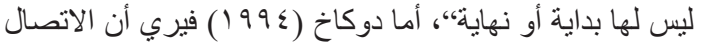

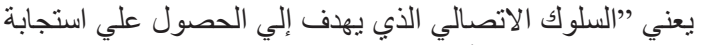

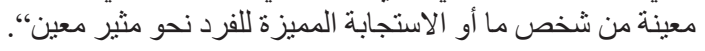

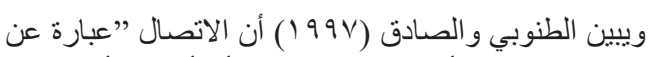

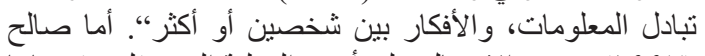

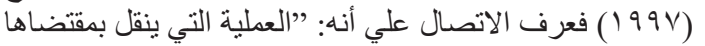

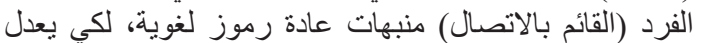

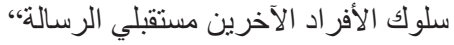

يتبين من العرض السابث أن الاتصال هو عبارة عن العملية

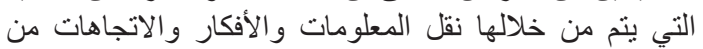

أفر اد متباينين في الخصائص الثخصية والمستويات الاجتماعية

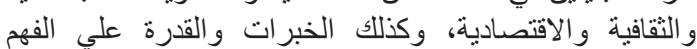

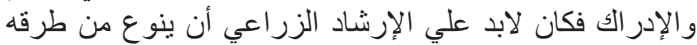

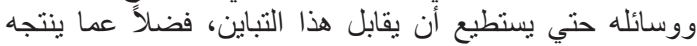

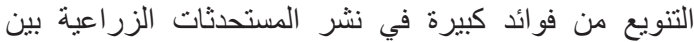
جمهور المسترشدين، (john, 2010).

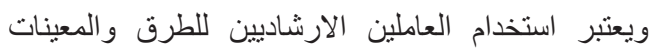

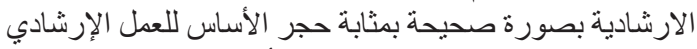

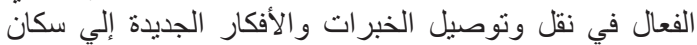

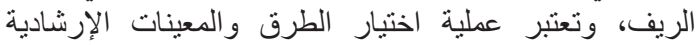

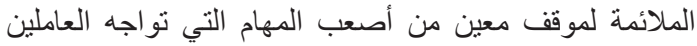

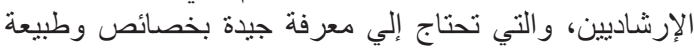

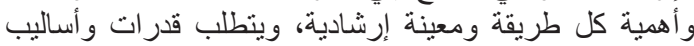

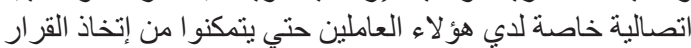

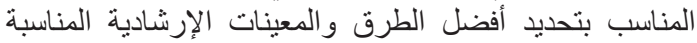

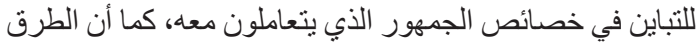

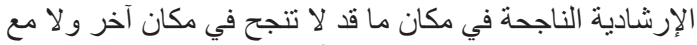

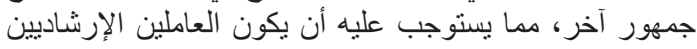

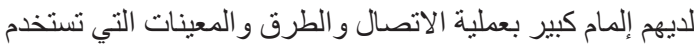

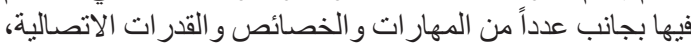

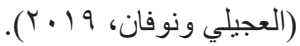

ويعد الاتصال الجيد جو هر العمل الإرشادي حيث أن المشكلة

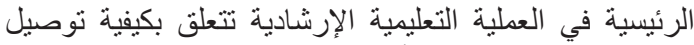

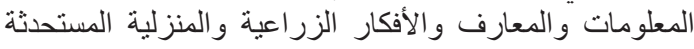
إلي جمهور الزر اع وربات البيوت الريفيات بطريقة تحفز هم علي الزئي

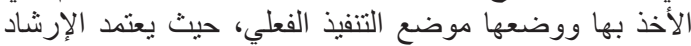
الزر اعي في توصيل رسالته إلي المستهدفين علي استخدام وسائل التئل

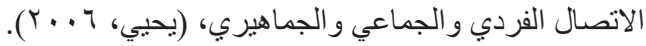

ويعاني الإرشاد الزر اعي من أوجه قصور في طرقه ووسائله

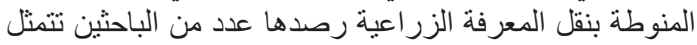

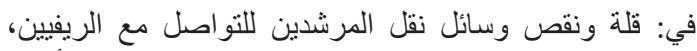

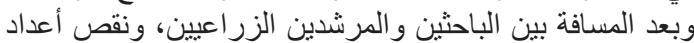

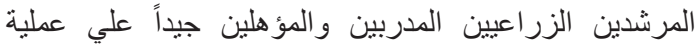

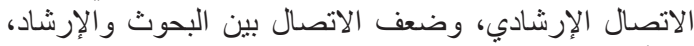

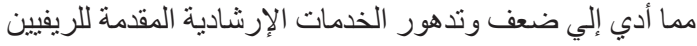

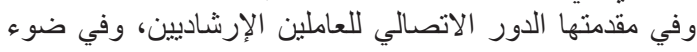

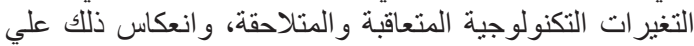

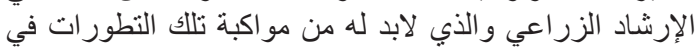

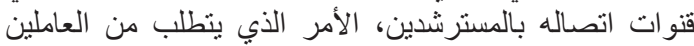

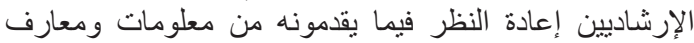

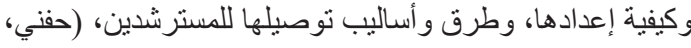

. ( r..人

لذا يعد هذ البحث محاولة للتعرف علي طبيعة الأنشطة

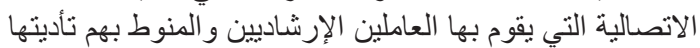

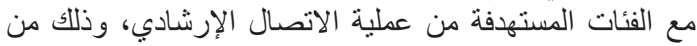

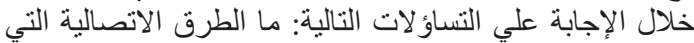

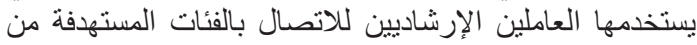

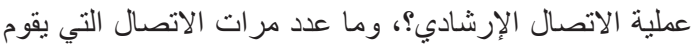

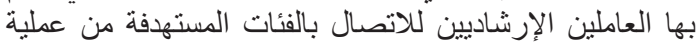

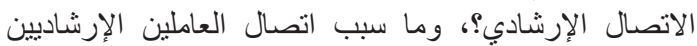

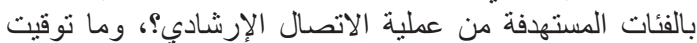
اتصال العاملين الإرشاديين بالفئات المستهدفة من عملية الاتصال

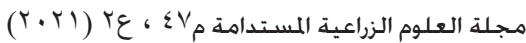


الاتصال هنا يتم دون هدف محدد، [ب] الاتصال الموجه و الاتصال

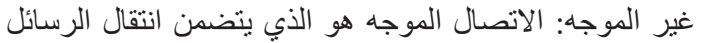

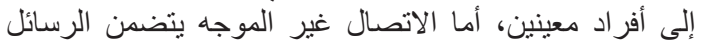

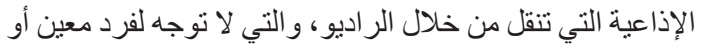

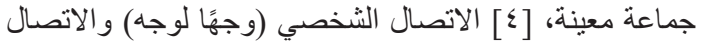

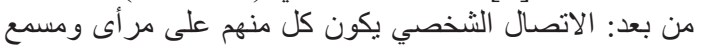

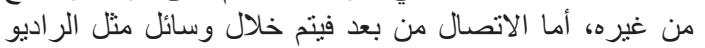

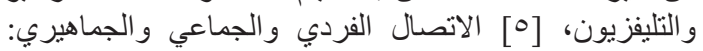

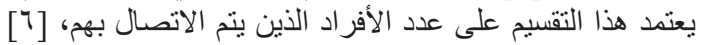

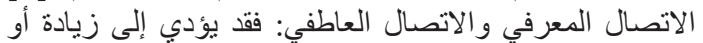

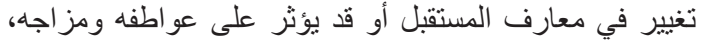

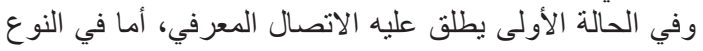
الآخر يطلق عليه الاتصال العاطفي.

رابعاً: عناصر الاتصال Communication Components:

قسم عودة (9919 (19) نقلاً عن كولمان ومارش عملية الاتصال إلي خمسة عناصر و هي: النيا:

1- الثخص أو الجماعة التي تبدأ بإرسال الرسالة ويطلق عليه

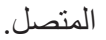
r r - محتوي الرسالة أو مضمونها.

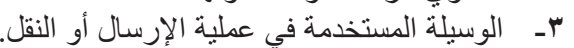
عـ - المستقبل أو المنصل به. هـ - الاستجابة التي يصدر ها هذا المستقبل.

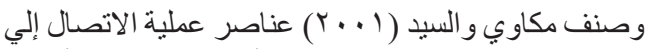

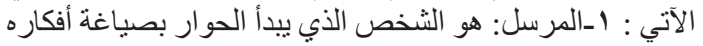

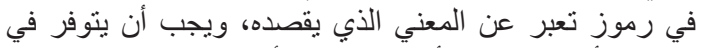

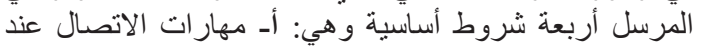

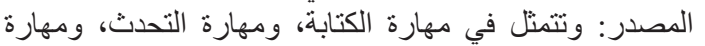

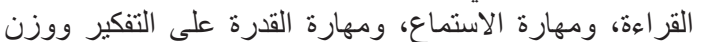

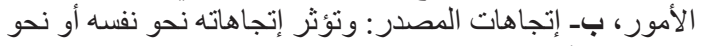

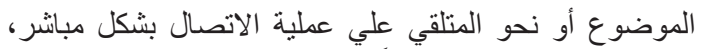

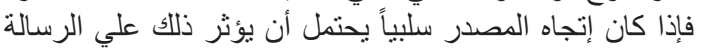

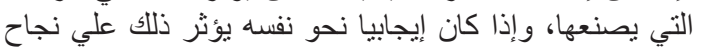

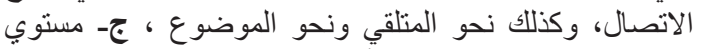

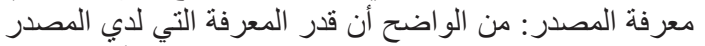

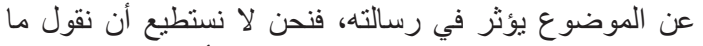

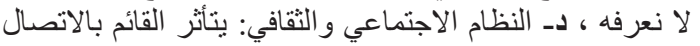

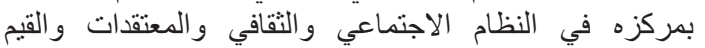

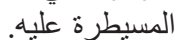
r- المتلقي: وكل مليه ما سبق ينطبق علي المتلقي.

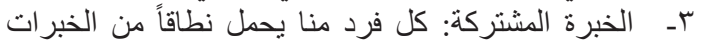

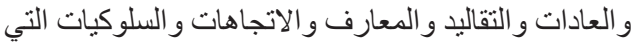

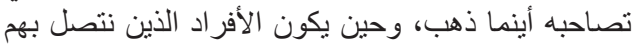

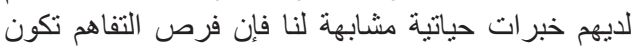

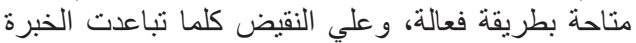
الحياتية بين المرسل و المتلقي كلما صعب وعلي التفاعل.

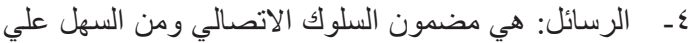

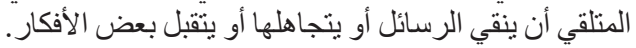

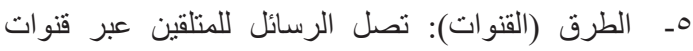

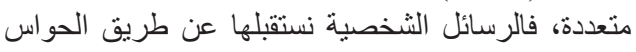

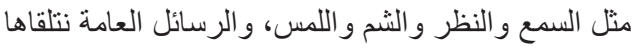
عبر وسائل الاتصال الجماهيرية من صحف ولالن ومجلات

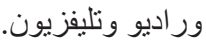

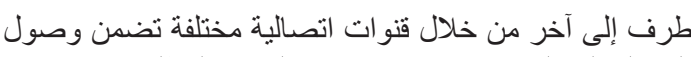
الرسالة إلي المستفيدين منها لإحداث التغيير المطلوب.

Extension Communication ثنانيًا: مفهوم الاتصال الإرشادي

:Concept

يبين الخولي ورزق (I9VV) أن الاتصال الإرشادي

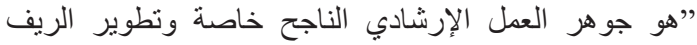

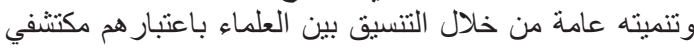

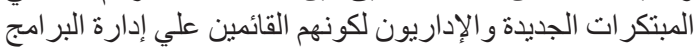

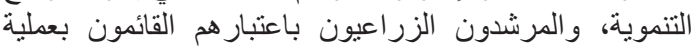
إيصال المكتشفات إلي جمهور المسترشئندين لتحسين مستوياتهم

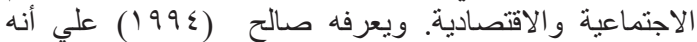

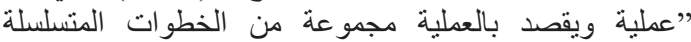
المرتبطة ببعضها البعض بوليثة بحيث تؤدي في النهاية الي إحراز هدف أو مجموعة من الأهداف.

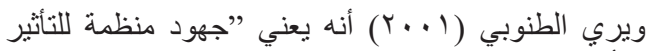

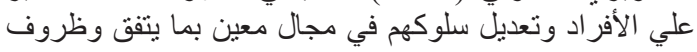

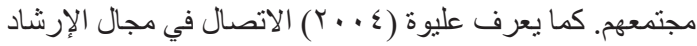

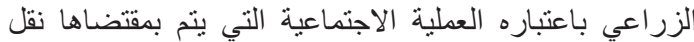

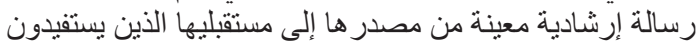
منها.

كما يعرفه قشطه (Y Y Y Y) بأنه "عملية توصبيل المعاني

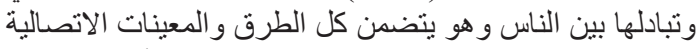

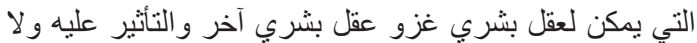

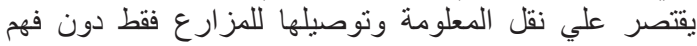
و واستيعاب.

ثالثًا: أنواع الاتصال' Communication Kinds:

يذكر العادلي (9VT) (9VT) تصنيف الاتصال على أساس

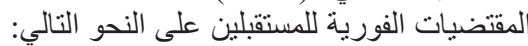

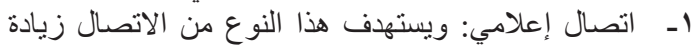

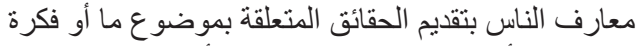

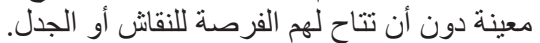

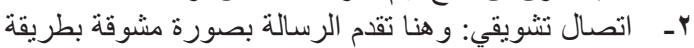

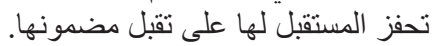

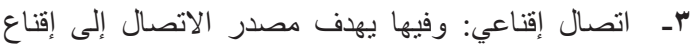

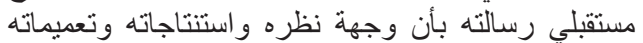

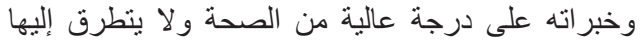

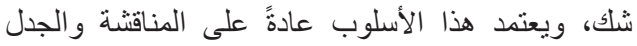
وتقديم الحقائق في صورة هنطقية الأبل مقبولة

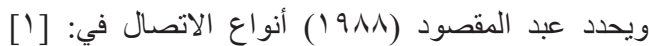

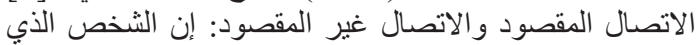

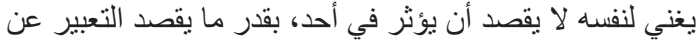

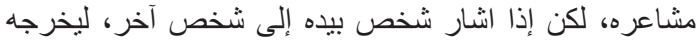

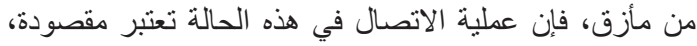

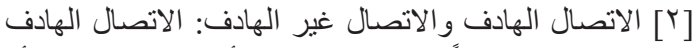

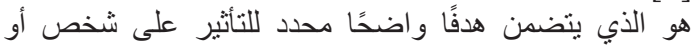

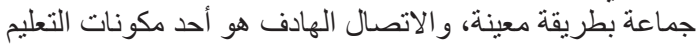

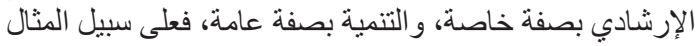

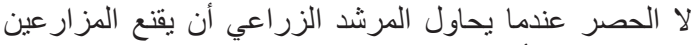

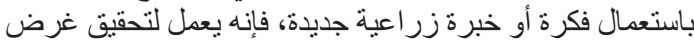

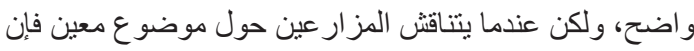

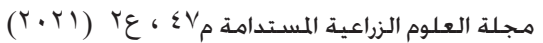


هـ جمهور المسترشدين: وهم مستقبلي الرسالة الإرشادية

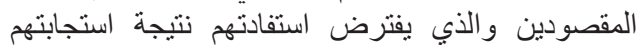
للاسلة الإرشادية بطريقة معينة.

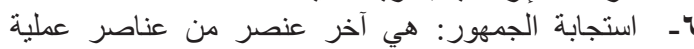

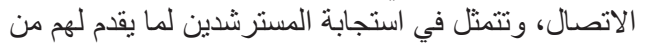

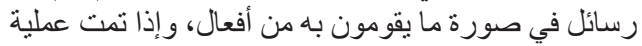

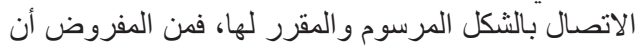

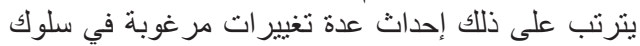
المسترشدين تتمثل في معار فهم ومهار اتهم و اتجاهاتهر.

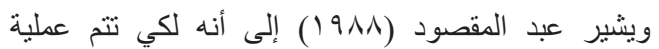

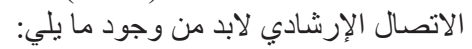

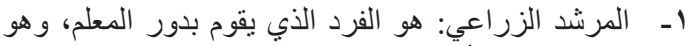

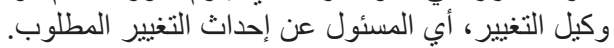

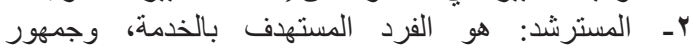

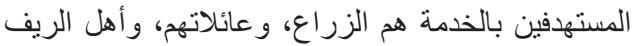
جميعًا. r- الرسالة الإرشادية: وهي تتضمن المعاد المعاتومات والأفكار

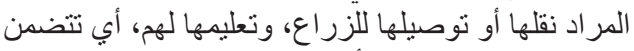
كل ما يدور حول الفكرة أو الثيء لتون الجديد.

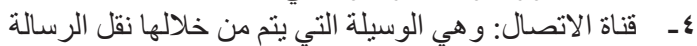
من المرشد إلى المسترشد.

ويؤكد علي أن هذه العناصر ضرورية ولكنها ليست

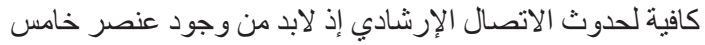
لحدوث هذا الاتصال و هو الاستجابة.
T- - التشويش: وهو أي عائق يحول دون القدرة علي الإرسال

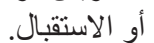

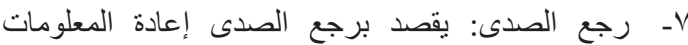

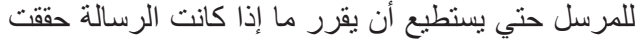

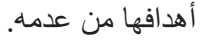

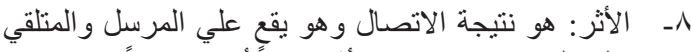
علي السواء، وقد يكون الأثر نفسياً أو اجتماعياً.

خامساً: عناصر عملية الاتصال الإرشادي Components of :Extension Communication

بري العادلي ( 1 ( ) نقلاً عن ليجانز Leganes أن عملية

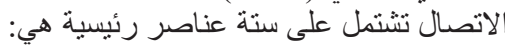

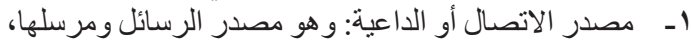

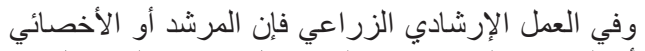

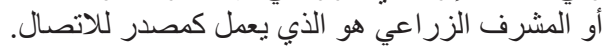

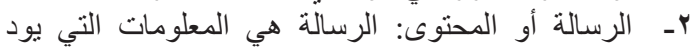

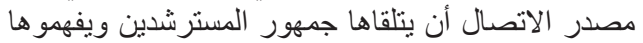
ويعملو ا بهديها.

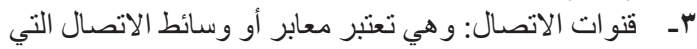

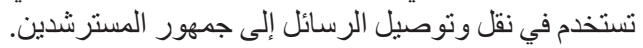

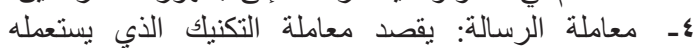

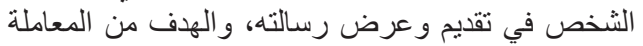

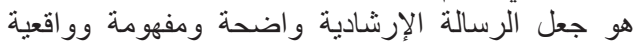
بالنسبة للمسترشدين.

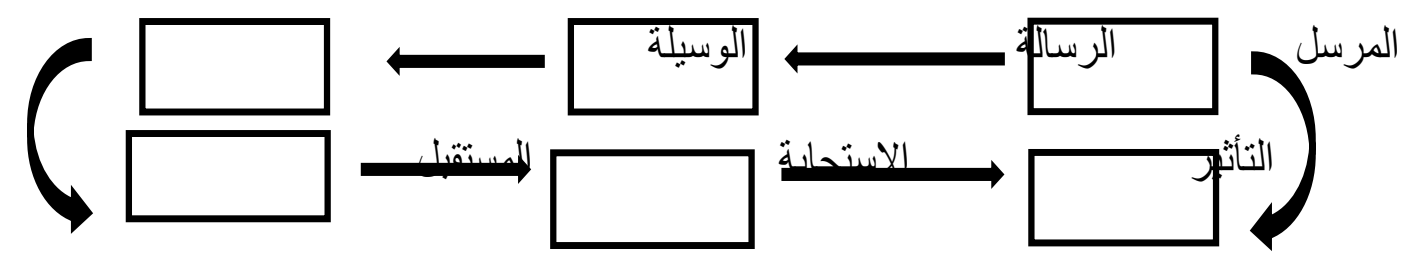

شكل 1. عناصر عملية الاتصال

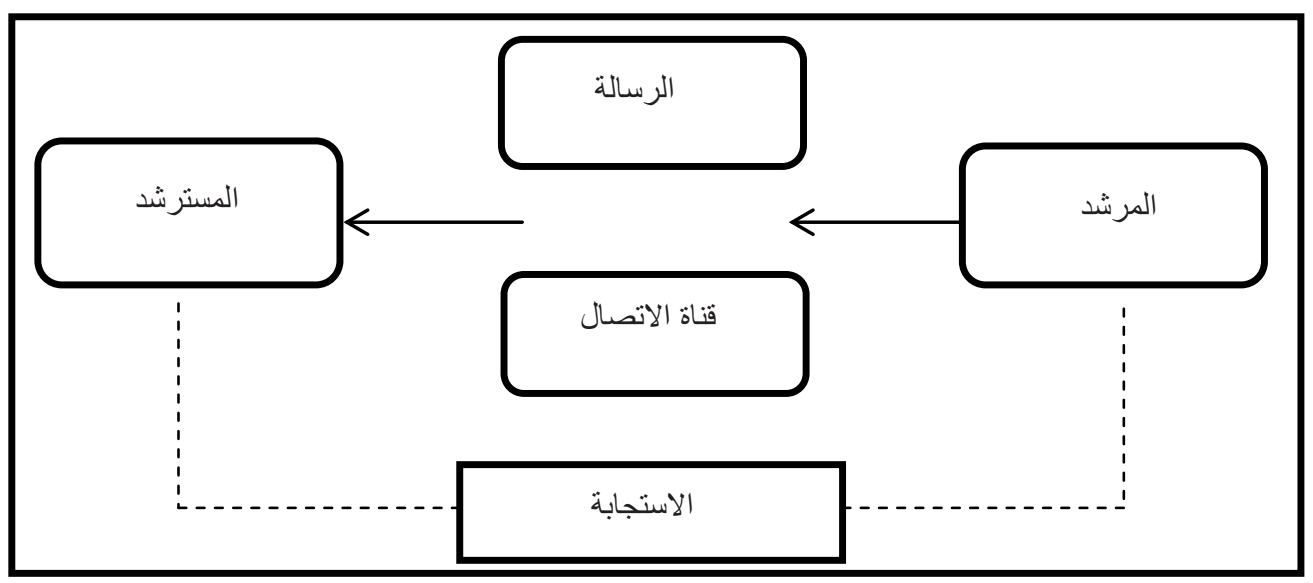

شكل Y. عناصر عملية الاتصال الإرشادي

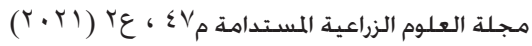




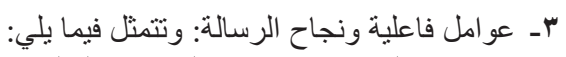

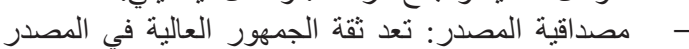
هي أساس التعرض للرسالة وهي العامل المؤثر في فاعلية

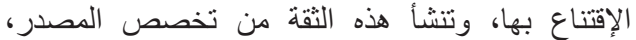

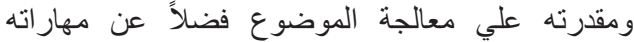
الاتصالية ومركزه الاجتماعي. الثقة في الوسيلة: مدي الثقة التي بوليها الجمهور للوسيلة عاملاً هاماً في التعرض لتنالك الوسيلة والاقتناع بما تبثه

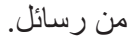

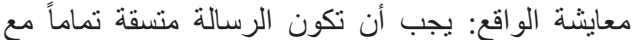

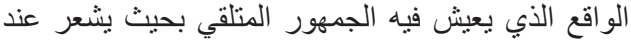
التعرض التلائ الرسالة بأنها معايشة للواقع تماماً وتلبي احتباجاته المعرفية والثقافية و العلمية .... إلخ.

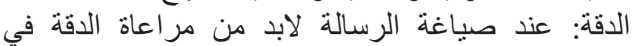

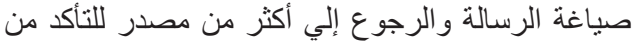
دقة المعلومات التي تحتويها، وكلما كانت دقيقة كلما كانت أكثر مصداقية للمتلقي.

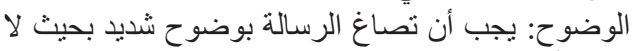

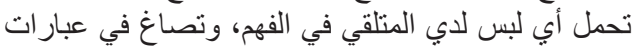

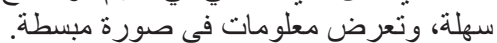

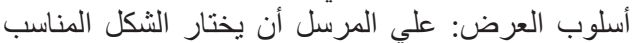

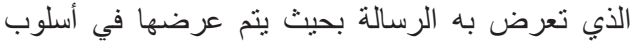

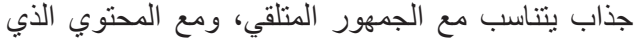
تتضمنه الرسالة حتي تنال إهتمام الجمهور المتلقي.

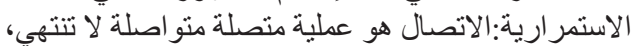
كما أن للنكرار أهميته الخاصة لضمان لإن اجتذاب أكبر عدد

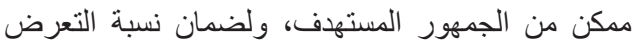
إلي الرسالة الإعلامية و إدر اكها علي النحو المطلوب، ولنه و هنا

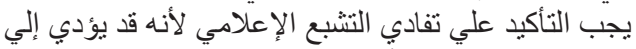

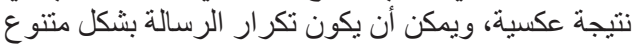
لضمان زيادة التأثير. الموضوعية: بمعني أن الرسالة لابد أن تنقل الحقائق المجردة إلي الجمهور بدون تحيز أو ذاتية.

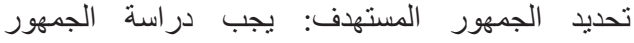

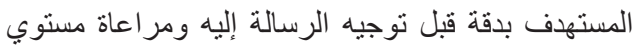

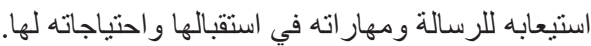

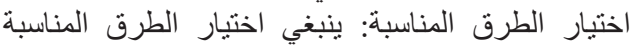

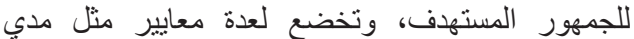
صلاحية تلك الطرق، وكثافة التعرض لها، ومدي انتثار

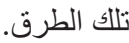

عـ عوامل فاعلية ونجاح رجع الصدى أو التغذية العكسية:

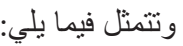

هو اتصال راجع من المستقبل إلي المرسل بحيث يتيح لللمرسل المجال للحصول علي معلومات التمات عن مدي تفاعل المنلقي

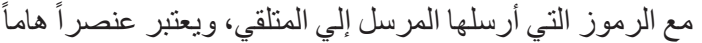

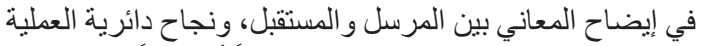
الآتصالية، وقد يكون رجع الصدى إيجابياً أو سلبياً ، فالإيجابي الئي

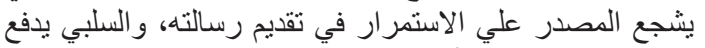

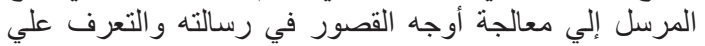

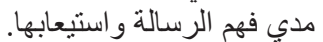

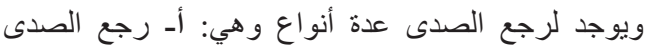

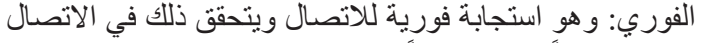
الفردي وجهاً لوجه ونسبياً في الاتصال الجماعي و الجماهيري.

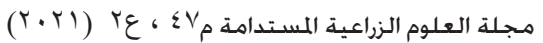

سادساً: عو امل فاعلية ونجاح مصادر عملية الاتصال: Effective factors and success of the sources of communication process:

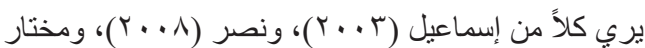

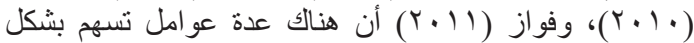

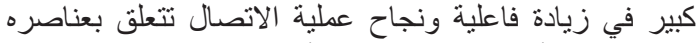

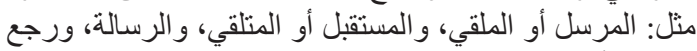
الصدى أو التغذية العكسية، والوسيلة المستخدمة. ونتناولها علي التئي

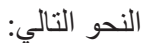

ا- عو امل فاعلية ونجاح المرسل أو الملقي: وتتمثل فيما يلي:

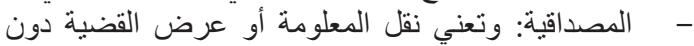

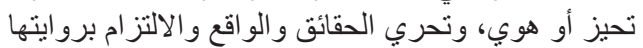

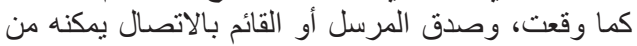

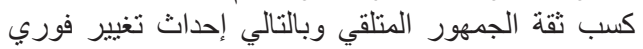
لاي الجمهور أكثر من عوامل أخري مثل جاذبية وقبول فئل فئل

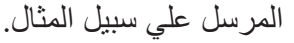
الإيمان بالقضية والفهم الدقيق لها: يعد الإيمان العميق

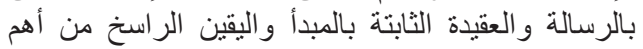

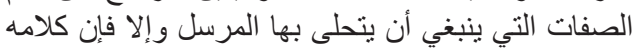

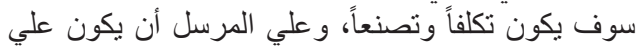

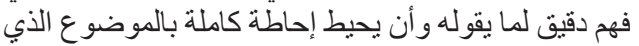
يقدمه وملم بكافة جو انبه و أخر تطور اتهـ

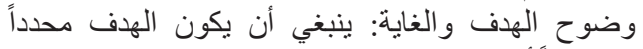

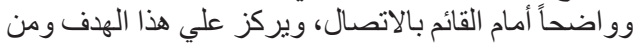
ثم لا ينبغي الخلط بين أكثر من موضوك عل أو أو تصيد أفكار و عبار اتليس بينها رابط و لا تخدم الهدف الأساسي الذي لئي صاغ من أجله الرسالة.

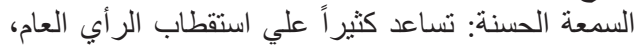

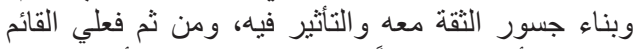

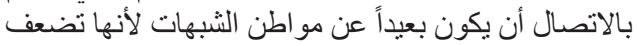

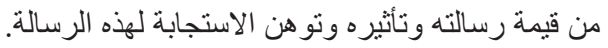

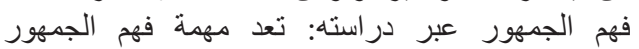

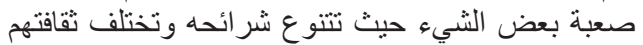

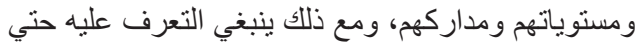
يمكن تقديم الرسالة التي تتناسبه وتلائمه، وتحقيق أكبر

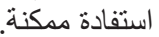
الجاذبية والتثويق: إذا كان الجمهور يتباين في أثشياء

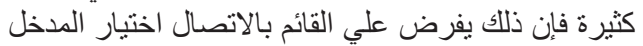

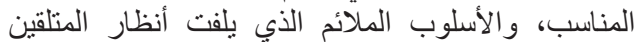
للرسالة مثل مقدمة جيدة ومشوقة تعمل علي جذبهم للمرسل.

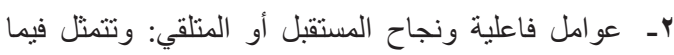

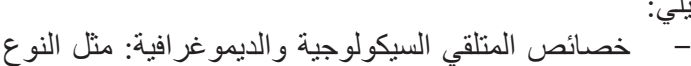

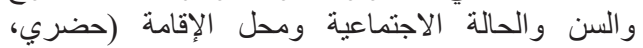

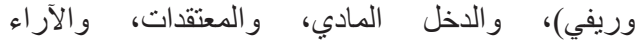
و الإتجاهات، و القيم و الميول، والطموح و التطلعات ل... إلخ. هناك العديد من المضامين الإعلامية للرسالة التي توجهات التهات

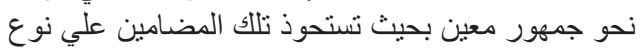

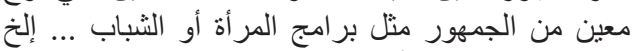

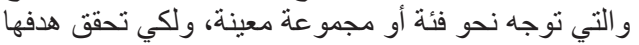
لابد أن يكون المرسل علي دراية تامة بخصائص ذلك الجمهور وصفاته. 
ع - بعد المسافة الاجتماعية بين المرشد الزر اعي و المسترشدين

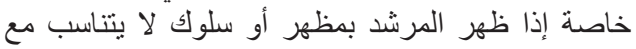
الوضع الاجتماعي للمسترشنين. هـ - الوقت غير الكافي أو غير المناسب لإرسال واستقبال الرسالة. - (الوقات.

7- اختلاف مهارات الاستقبال لاي الجمهور، كما يحدث الماث

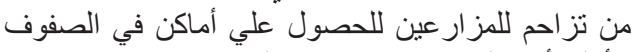

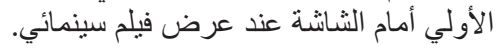

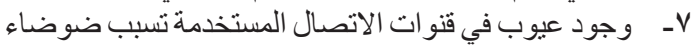
تعوق وصول الرسالة، وذللك مثل استخدام مكبر ات اتل للصوت

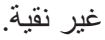

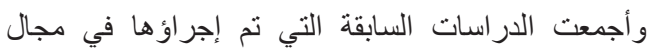

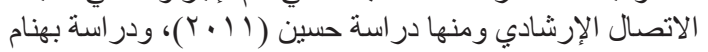

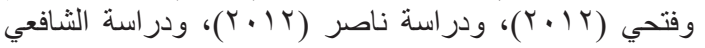

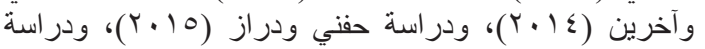

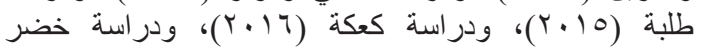

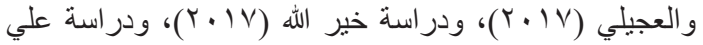

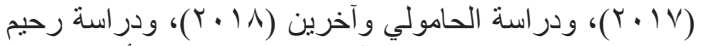

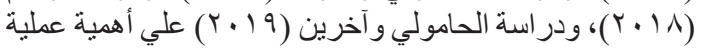

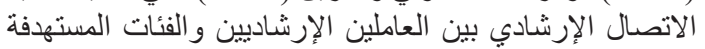

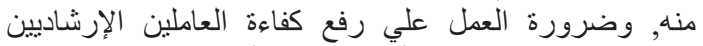

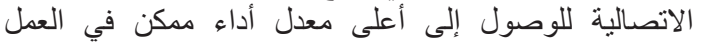

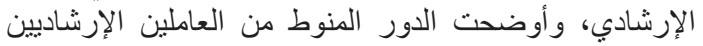

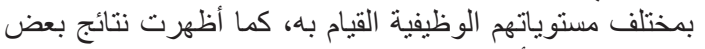

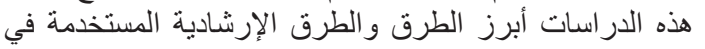

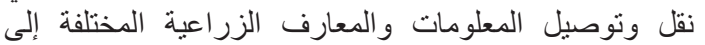
جمهور المسترشدين.

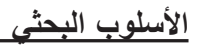

أو لاً: التعاريف الإجر ائية:

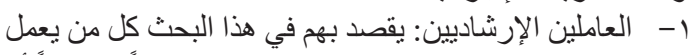

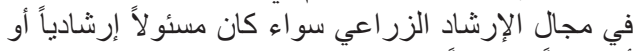

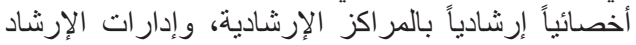

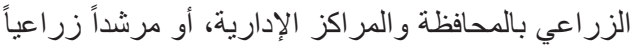
علي مستوي القرية. r- طبيعة الأنشطة الاتصالية للعاملين الإرشاديين: تم قياسها من

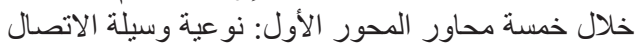

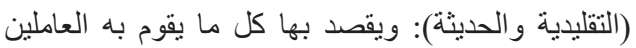

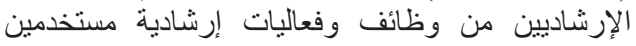

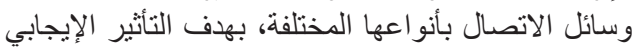

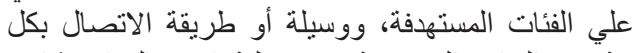

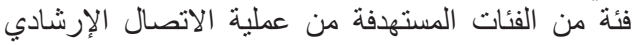

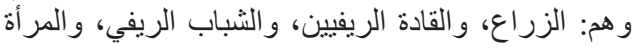

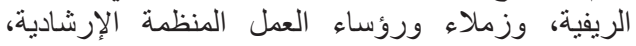

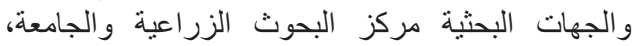

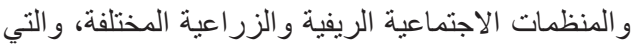

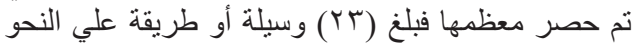

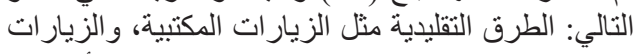

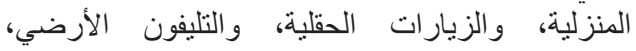

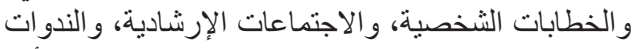

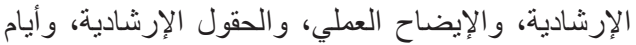

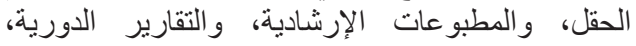

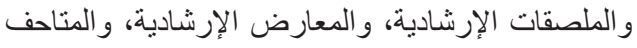

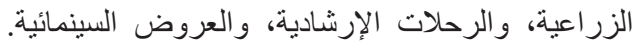

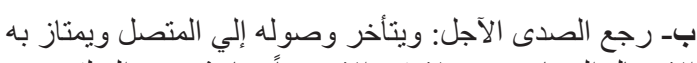

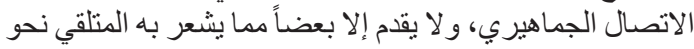

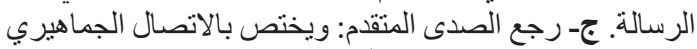

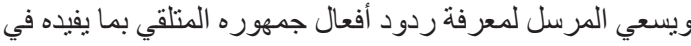
تعديل رسالته وتطوير ها. هـ عوامل فاعلية ونجاح الوسيلة المستخدمة:

وتتمثل فيما يلي: يحتاج أي اتصال إلي وسيلة لتوصيل

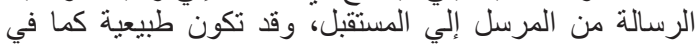

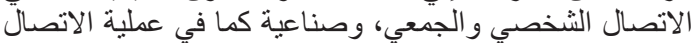

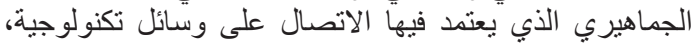

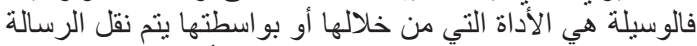

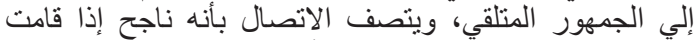

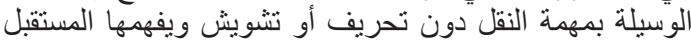
بالمعني الذي بريده المرسل.

وقد تكون الوسيلة في صورة آلات وأجهزة فنية قادرة علي

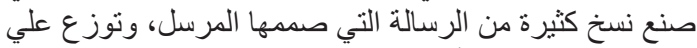

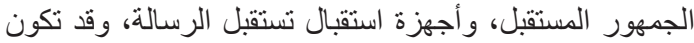

تلاك الطرق مقرو عة أو مسمو عة أو مرئية أو سمعية بصرية.

سابعاً: معو قات الاتصال الإرشادي Obstacles of Extension :Communication

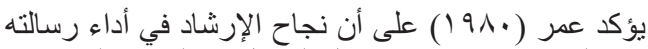

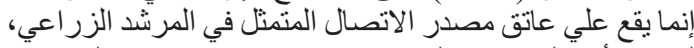

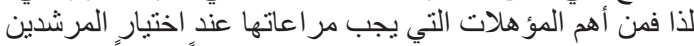

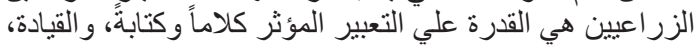
و القدرة علي التعليم، و القدرة علي التعائي التعل مع الغير.

أوضح العادلي (r/9 1 ) أن نجاح أو فنشل عملية الاتصال

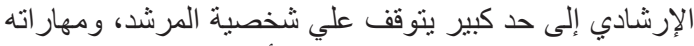

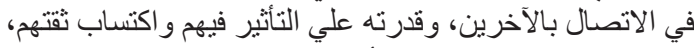

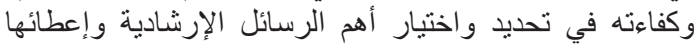

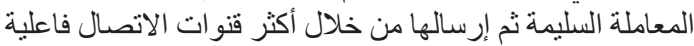
إلي جمهور المسترشدين.

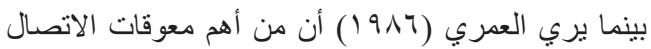

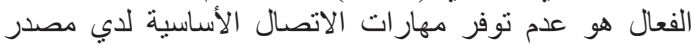

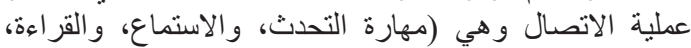

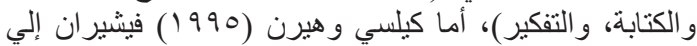

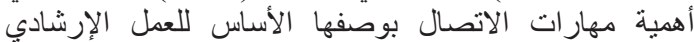

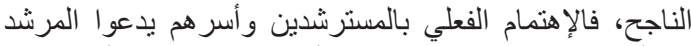

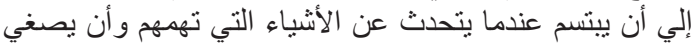

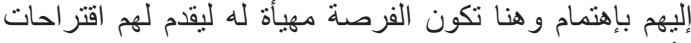

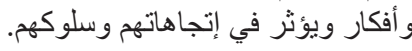

ويري سلام وشكري (1990) أن المشكلات التي تؤثر علي الاتصال الإرشادي تتمثل فيما يلي:

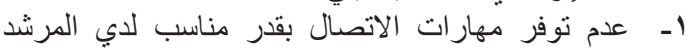

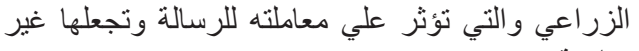

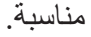
r - صعوبة إدر الك المعالجة التي شكلت بها الرسالة الإرشادية

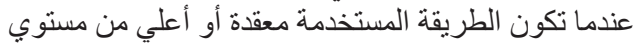
ثقافة المسترشدين.

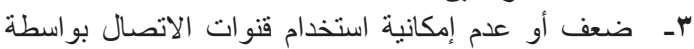

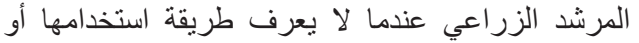
إدارنها بطريقة جيدة.

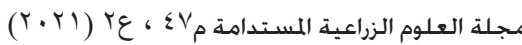


ثنالثاً: جمع وتحليل البيانات:

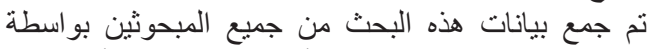

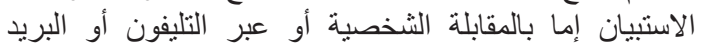

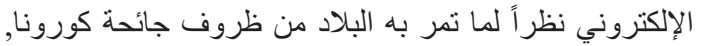

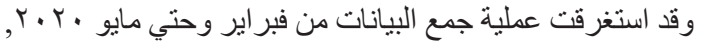

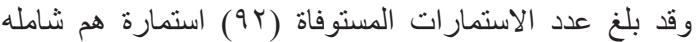

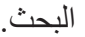

وبعد جمع البيانات ومراجعة استمار ات الاستبيان التي تم

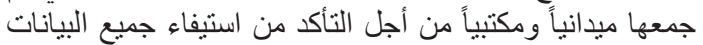

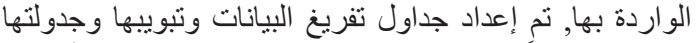
وتصنيفها وفقاً لمتطلبات البحث, وتم التمات استخدام عدة أساليب و أدو ات إحصائية وهي: النسبة المئوية, و التكر ار ات, و والمتوسط النئ

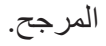

النتائج البحثية

أولاً: الطرق الاتصالية التي يستخدمها العاملين الارشاديين

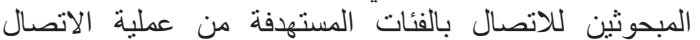

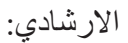

أـ الطرق المستخدمة للاتصال بالفئات المستهدفة من عملية الاتصال الإرشادي (التقليدية و الحديثة):

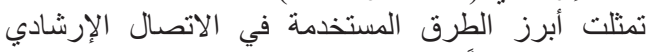

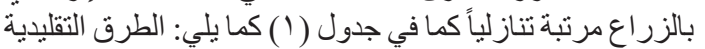

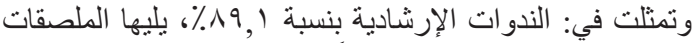

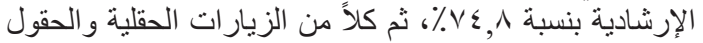

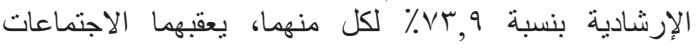

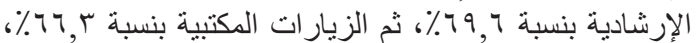

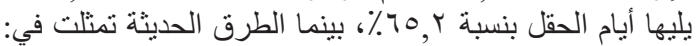

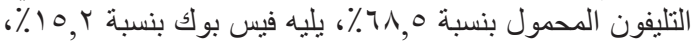

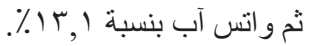

وجاءت أهم الطرق المستخدمة في الاتصال الإرشادي

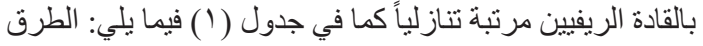

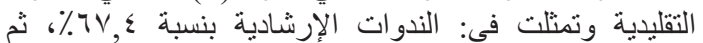

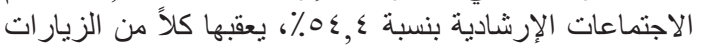

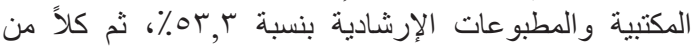

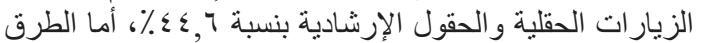

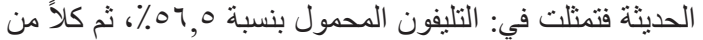

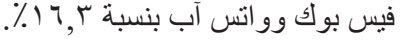

بينما تمثلت أهم الطرق المستخدمة في الاتصال الإرشادي

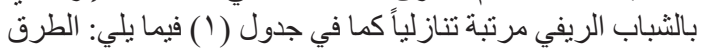

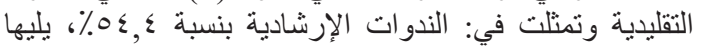

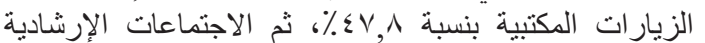

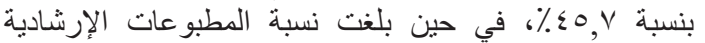

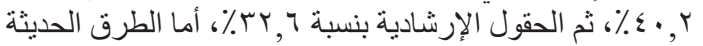

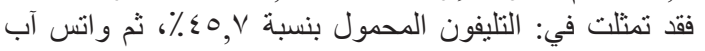

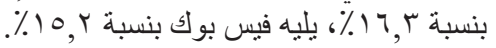

أما المر أة الريفية فكانت أهم الطرق المستخدمة في الاتصال

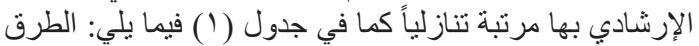

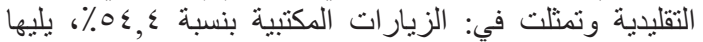

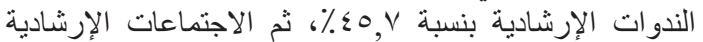

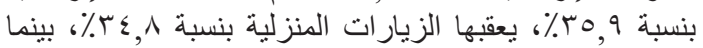

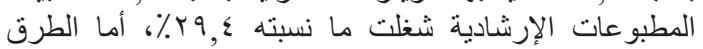

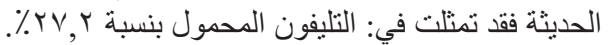

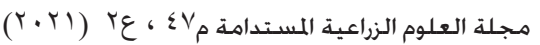

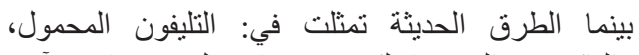

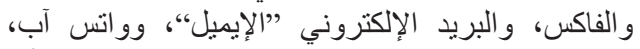

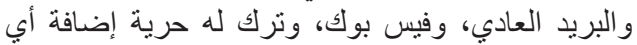

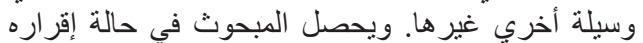

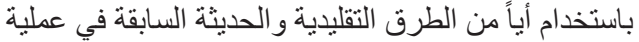

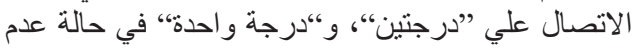

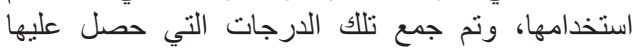
المبحوث لتعبر عن محور وسيلة الاتصال المستخدمة في الإني

عملية الاتصال الإرشادي مع الفئات المستهدفة السابقة.

المحور الثاني: عدد مرات الاتصسال بأطراف العلاقة

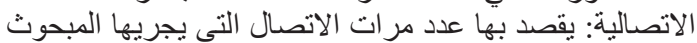

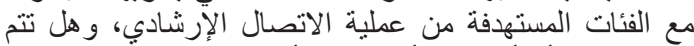

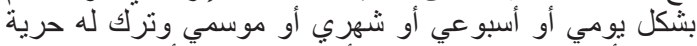

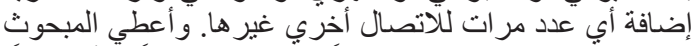

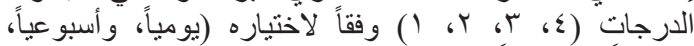

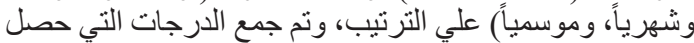

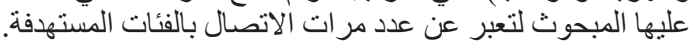

المحور الثالث: سبب الاتصال بأطر اف العلاقة الاتصالية:

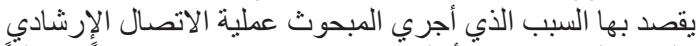

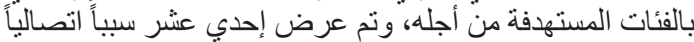

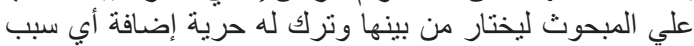

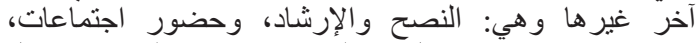

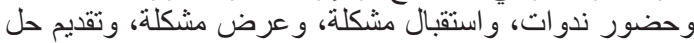

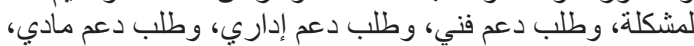

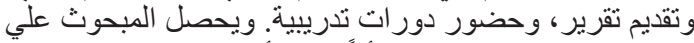

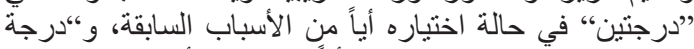

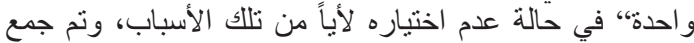

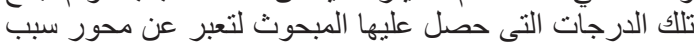
الاتصال بالفئات المستهدفة من عملية الاتصال الإرشادي. لعني

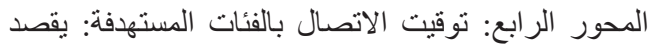

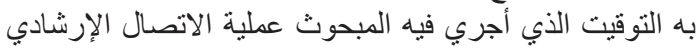

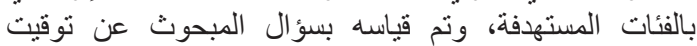

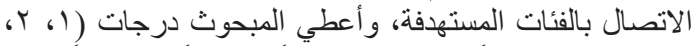

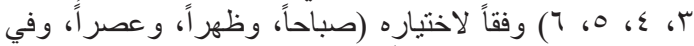

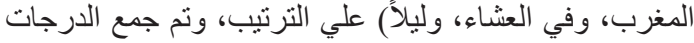

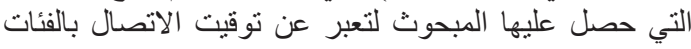

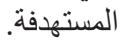

المحور الخامس: شكل الاتصال بأطر اف العلاقة الاتصالية:

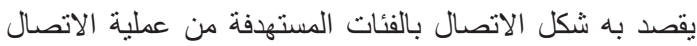

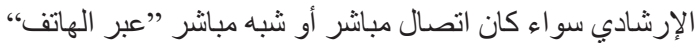

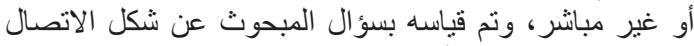

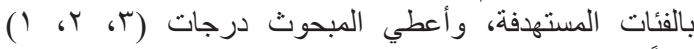

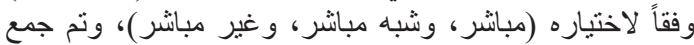

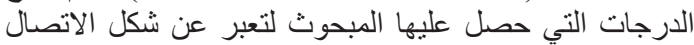

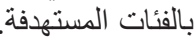

ثانياً: منطقة وشاملة البحث:

تم إجر اء هذا البحث علي جميع البح العاملين الإرشاديين بالجهاز

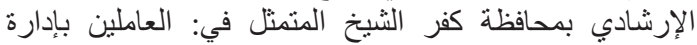

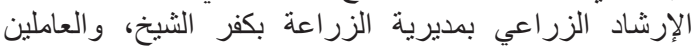

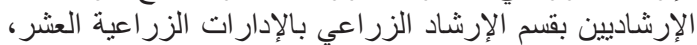

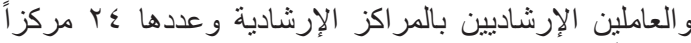

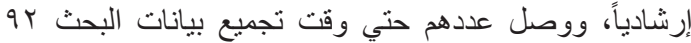
عاملاً إرشادياً، 
جدول ا. طرق اتصالالعاملين الارشاديين المبحوثين بالفئات المستهذفة من عملية الاتصال الإرشادي

\begin{tabular}{|c|c|c|c|c|c|c|c|c|c|}
\hline \multirow{3}{*}{ لعدوسط مرات } & \multicolumn{8}{|c|}{ الفئات المستهدفة } & \multirow{3}{*}{ في الاتصال } \\
\hline & \multicolumn{2}{|c|}{ المرأة الريفية } & \multicolumn{2}{|c|}{ الثباب الريفي } & \multicolumn{2}{|c|}{ القادة الريفيين } & \multicolumn{2}{|c|}{ الزراع } & \\
\hline & $\%$ & العدد & $\%$ & العدد العد & $\%$ & العدد العد & $\%$ & العدد العد & \\
\hline 00,0 & $0 \leqslant, \leqslant$ & 0. & $\varepsilon \vee, \wedge$ & $\varepsilon \varepsilon$ & r r & $\leqslant 9$ & $77, r$ & 71 & الزيار ات المكتبية \\
\hline$r v, 1$ & $r \varepsilon, \wedge$ & r & $r \wedge, r$ & YT & $r q, 1$ & ד & $\varepsilon r, \varepsilon$ & rq & الزيار ات المنزلية \\
\hline$\varepsilon 1,7$ & 19,7 & 11 & $r \wedge, r$ & $r t$ & $\varepsilon \varepsilon, 7$ & « & $v r, q$ & $\uparrow$ & الزيار ات الحقلية \\
\hline $0, \mathrm{~V}$ & $\because \cdot$ & صفر & $V, T$ & v & $1 \leq, 1$ & r & $1 \cdot, 9$ & 1. & التليفون الأرضي \\
\hline$\varepsilon, 1$ & $\cdot$, & صفر & $r, r$ & r & $v, \wedge$ & v & $0, \varepsilon$ & 。 & الخطابات الثخصية \\
\hline $01, \varepsilon$ & $r_{0,9}$ & 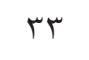 & $\leqslant 0, V$ & $\varepsilon r$ & $0 \leqslant, \leqslant$ & o. & 79,7 & $T \leqslant$ & الاجتماعات الإرشادية \\
\hline$T \leqslant, Y$ & $\varepsilon 0, V$ & $\leqslant r$ & $0 \leqslant, \varepsilon$ & 0 . & $T V, \varepsilon$ & $\pi$ & 19,1 & Ar & الندو ات الإرشادية \\
\hline$r \wedge, \wedge$ & $W, \varepsilon$ & 17 & $r_{1}, r$ & $r$. & $\mu, 0$ & rq & $\varepsilon \varepsilon, 7$ & « & الإيضـاح العملي \\
\hline$\varepsilon 1, r$ & $1 \leqslant, 1$ & r & rr, & $r$. & $\varepsilon \varepsilon, 7$ & «1 & $v r, q$ & $\uparrow$ & الحقول الإرشادية \\
\hline$r q, 1$ & $W v, \varepsilon$ & 17 & $r \cdot, \varepsilon$ & rA & $\varepsilon r, 0$ & $\varepsilon$. & $70, r$ & 7. & أيام الحقل \\
\hline$\leqslant 0,9$ & $r q, \varepsilon$ & rV & $\varepsilon \cdot, r$ & rV & or, & $\leq 9$ & $7 \cdot, 9$ & 07 & المطبو عات الإرشادية \\
\hline ro, & rr, & 11 & $r r, q$ & rr & $r q, \varepsilon$ & rV & $V \varepsilon, \wedge$ & $\varepsilon \varepsilon$ & الملصقات الإرشادية \\
\hline$v, q$ & $\cdot \cdot$ & صفر & 7,0 & 1 & $1 \%$ & ir & ir, & 11 & الرحلات الإرشادية \\
\hline$\leqslant 9,0$ & $r V, r$ & ro & $\leq 0, V$ & $\varepsilon r$ & 07,0 & or & $7 \wedge, 0$ & Tr & التليفون المحمول \\
\hline r,o & $\because \cdot$ & صفر & $r, r$ & r & $\varepsilon, r$ & $\varepsilon$ & $r, r$ & r & 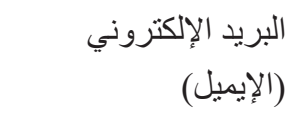 \\
\hline $11, \varepsilon$ & $\because \cdot$ & صفر & $17, r$ & 10 & $17, r$ & 10 & 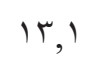 & ir & و انس آب \\
\hline $1, v$ & $\cdot \cdot$ & صفر & $r, r$ & r & $r, r$ & r & $r, r$ & r & البريد العادي \\
\hline ir, & $0, \varepsilon$ & 0 & $10, r$ & $1 \leqslant$ & $17, r$ & 10 & $10, r$ & $1 \varepsilon$ & فيس بوك \\
\hline
\end{tabular}

المكتبية بنسبة 9,1ا7٪، يليها الاجنماعات الإرشادية بنسبة

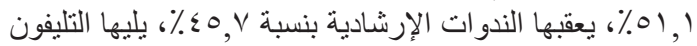

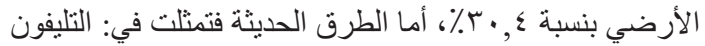

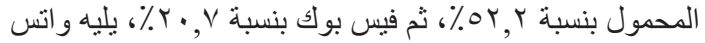

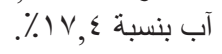

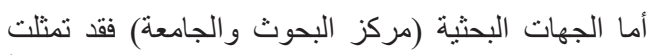
أهم الطرق المستخدمة في الاتصال بتلك الجهات مرتبة تنازلياً

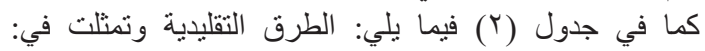

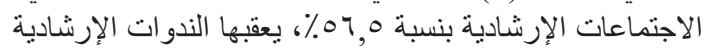

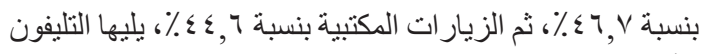

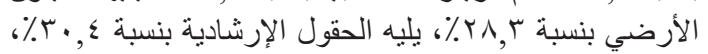

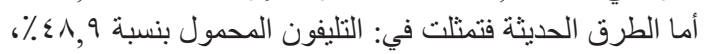

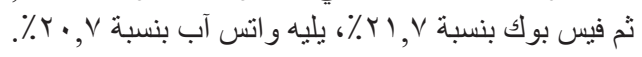

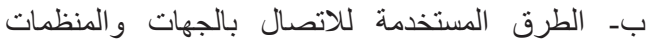
الرسمية من جانب العاملين الارشاديين المبحوثين:

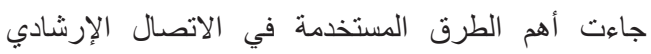

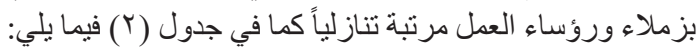

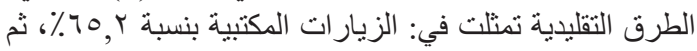

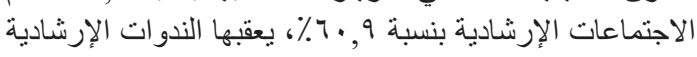

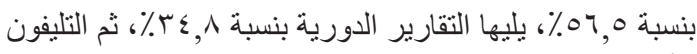

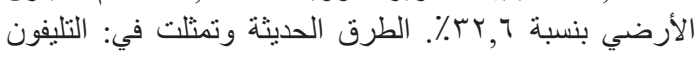

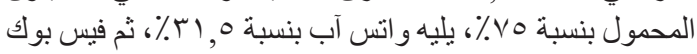

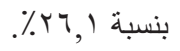

بينما تمثلت أهم الطرق المستخدمة في الاتصال الإرشادي

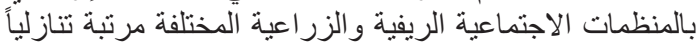

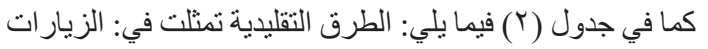

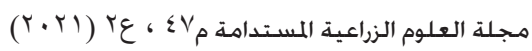


جدول ז. طرق اتصال العاملين الإرشاديين المبحوثين بالجهات والمنظمات الرسمية المستهدفة من عملية الاتصال الإشادي

\begin{tabular}{|c|c|c|c|c|c|c|c|c|}
\hline \multirow{3}{*}{ لعتوسط مرات } & \multicolumn{6}{|c|}{ الجهات والمنظمات الرسمية } & \multirow{3}{*}{ فيقي الاتصال المستخدمة } & \\
\hline & \multicolumn{2}{|c|}{ (مركز البحوثة) } & \multicolumn{2}{|c|}{ 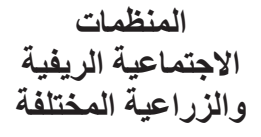 } & \multicolumn{2}{|c|}{ زداء ورؤساء العمل مقر العمل) } & & \\
\hline & $\%$ & 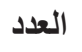 & $\%$ & 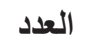 & $\%$ & 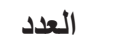 & & \\
\hline$o v, r$ & $\varepsilon \varepsilon, 7$ & « & 71,9 & ov & $70, r$ & 7. & الزيار ات المكتبية & \\
\hline$r \cdot, \varepsilon$ & $r \wedge, r$ & r & $r \cdot, \varepsilon$ & rی & $r, T$ & r. & التليفون الأرضي & $\overline{7}$ \\
\hline $17, r$ & $17, r$ & 10 & $1 \leqslant, 1$ & ir & 11,0 & iv & الخطابات الثخصية & : \\
\hline $07, r$ & 07,0 & or & 01,1 & $\varepsilon V$ & $7 \cdot, 9$ & 07 & الاجتماعات الإرشادية & \\
\hline$\varepsilon 9,7$ & $\leq 7, V$ & $\varepsilon r$ & $\varepsilon 0, V$ & $\leqslant r$ & 07,0 & or & الندو ات الإرشـادية & \\
\hline$i v, \wedge$ & $r \cdot, r$ & 19 & $1 \cdot, 9$ & 1. & 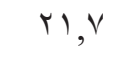 & $r$. & الإيضـاح العملي & $\sqrt{3}$ \\
\hline$r, O$ & ro, & $r r$ & 11,0 & iv & $r r, q$ & rr & المطبو عات الإرشادية & \\
\hline$r \leqslant, 7$ & $r, r$ & $r$. & $1 V, \varepsilon$ & 17 & $r \varepsilon, \wedge$ & rt & التقارير الدورية & \\
\hline$r \cdot, r$ & $1 \leqslant, 1$ & 14 & $r \cdot, r$ & 19 & $r v, r$ & ro & الملصقات الإرشادية & \\
\hline ir, & $1 \cdot, 9$ & 1. & ir, & 11 & $17, r$ & 10 & المتاحف الزراعية & \\
\hline ir, & $10, r$ & $1 \varepsilon$ & $1 \cdot, 9$ & 1. & $10, r$ & $1 \leqslant$ & الرحلات الإرشادية & \\
\hline$r_{0, \varepsilon}$ & $\varepsilon \wedge, q$ & $\leqslant 0$ & or,, & $\varepsilon \wedge$ & vo, & 79 & التليفون المحمول & \\
\hline$i v, \Lambda$ & 11,0 & iv & $1 V, \varepsilon$ & 17 & $1 V, \varepsilon$ & 17 & الفاكس & .7. \\
\hline $\mid v, 1$ & 19,7 & 11 & Ir, & 11 & 19,7 & 11 & البريد الإلكتروني (الإيميل) & $\overline{7}$ \\
\hline$r r, r$ & $r \cdot, r$ & 19 & $1 V, \varepsilon$ & 17 & r.,o & rq & واتس آب & \\
\hline$r r, \wedge$ & $r, r$ & $r$. & $r \cdot, r$ & 19 & $r 7,1$ & $r \leq$ & فيس بوك & \\
\hline
\end{tabular}

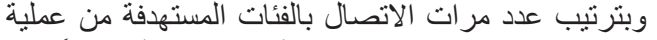

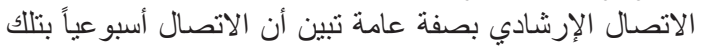

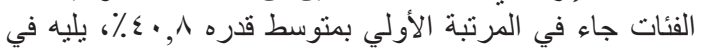

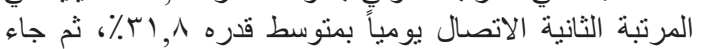

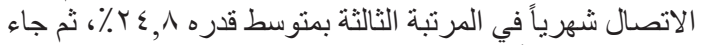

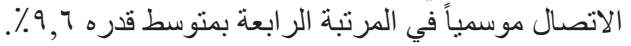

بـ عدد مر ات الاتصال بالجهات و المنظمات الرسمية:

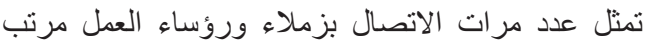

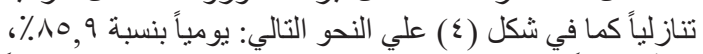

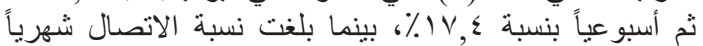

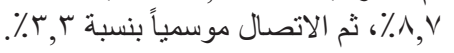

بينما تمثل عدد مر ات الاتصال بالمنظمات الاجتماعية الريفية

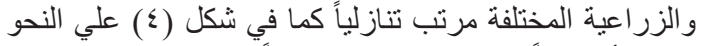

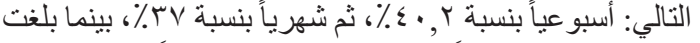

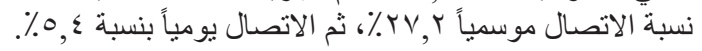

في حين تمثل عدد مرات الاتصال بالجهات البحثية (مركز

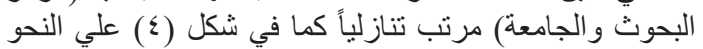

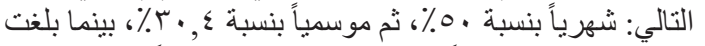

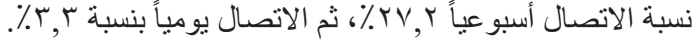

ثانياً: عدد مرات اتصال العاملين الارشاديين المبحوثين بأطر اف

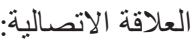
أـ عدد مرات الاتصالة الإل بالفئات المستهدفة من عملية الاتصـال

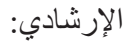

تمثل عدد مرات الاتصال بالزراع مرتب تنازلياً كما في

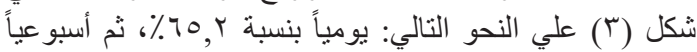

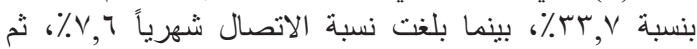

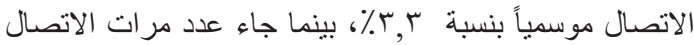

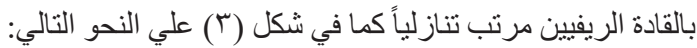

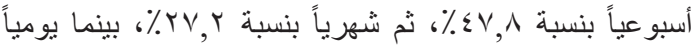

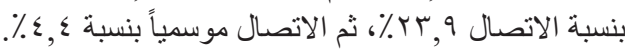
في حين جاء عدد مرات الاتصال بالثباب الريفي مرتب

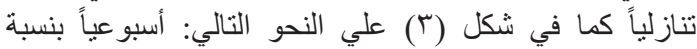

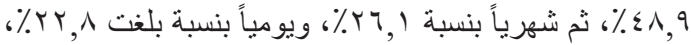

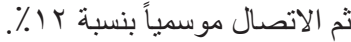

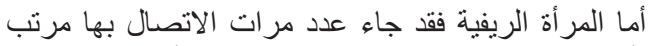

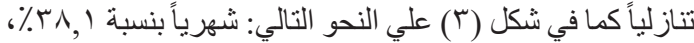

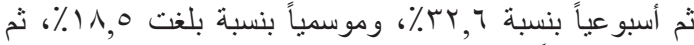

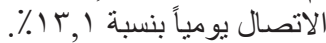

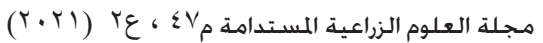




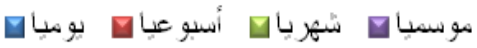

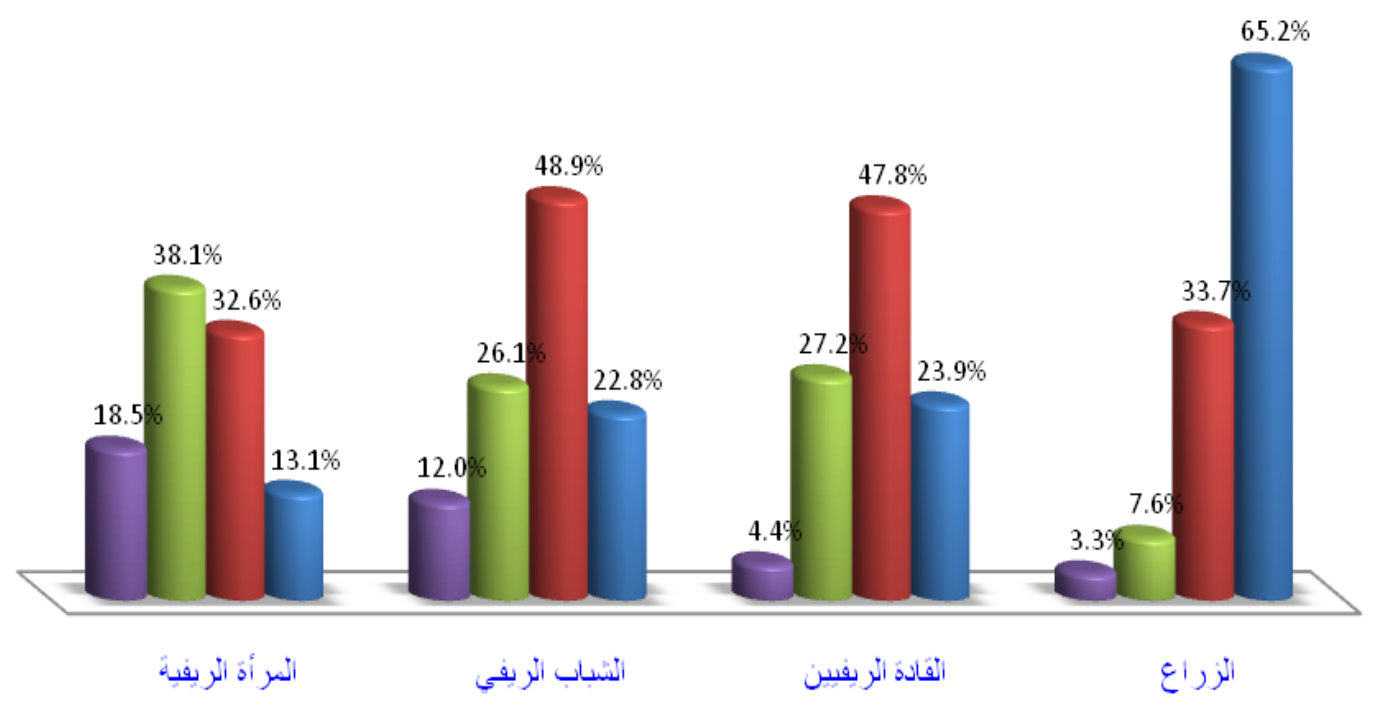

شكل r. عدد مرات اتصال المبحوثين بالفئات المستهذفة من عملية الاتصال الإششادي

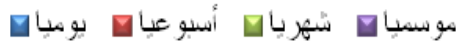

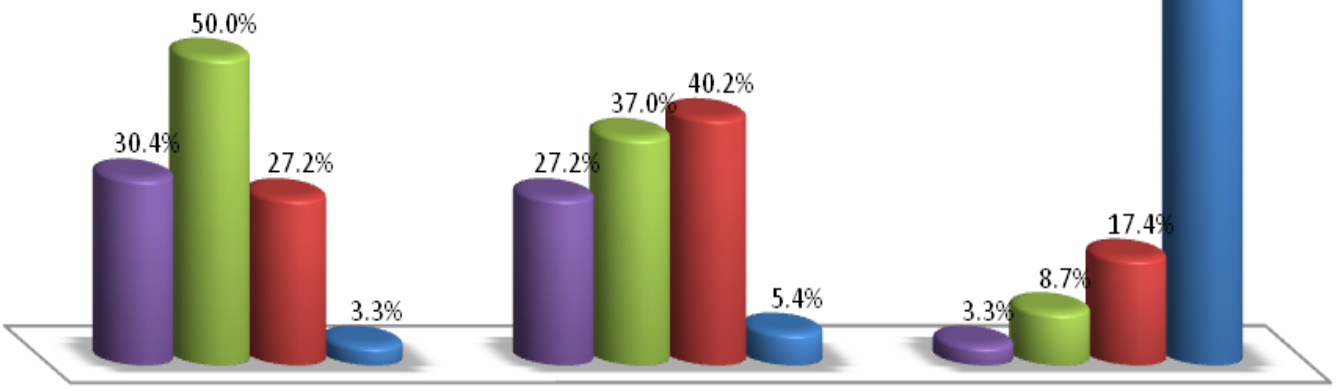

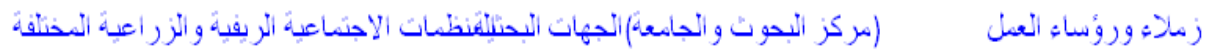

\section{شكل ؛. عدد مرات اتصال المبحوثين بالجهات والمنظمات الرسمية}

ثالثاً: أسباب اتصال المبحوثين بأطر اف العلاقة الاتصالية:

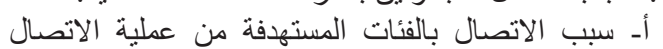

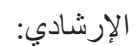

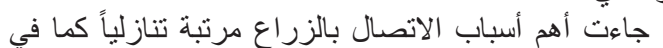

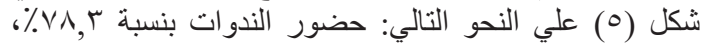

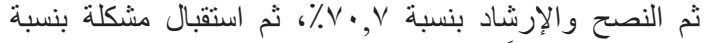

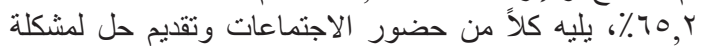

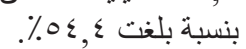

وبترتيب عدد مر ات الاتصال بالجهات و المنظمات الرسمية

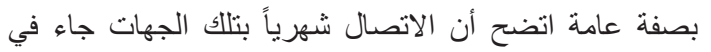

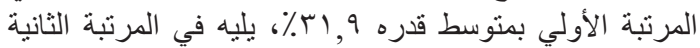

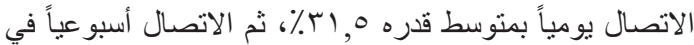

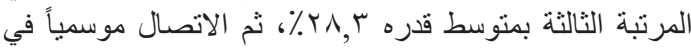

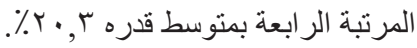


تنازلياً كما في شكل (7) علي النحو التالي: طلب دعم فني بنسبة

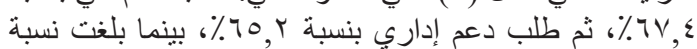

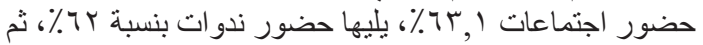

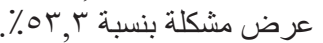

بينما تمثلت أهم أسباب الاتصال بالمنظمات الاجتماعية

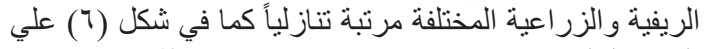

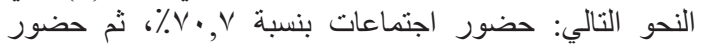

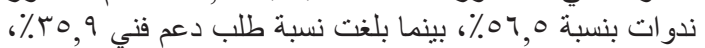

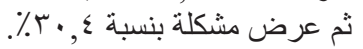

في حين تمثلت أهم أسباب الاتصال بالجهات البحثبة (مركز

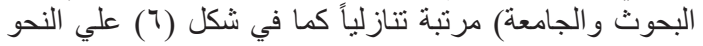

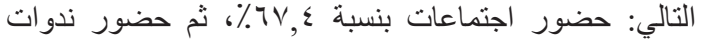

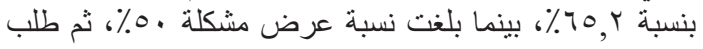

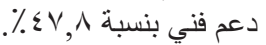

وبترتيب أهم أسباب اتصال المبحوثين بالجهات و المنظمات

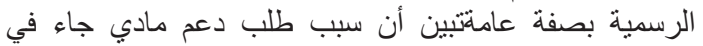

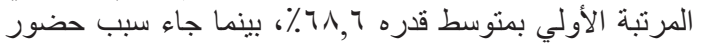

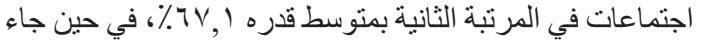

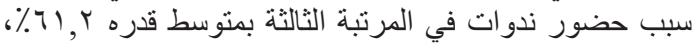

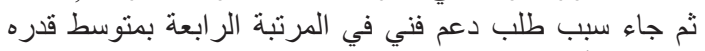

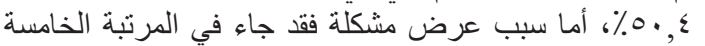

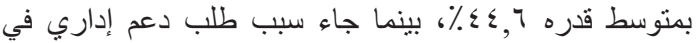

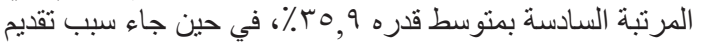

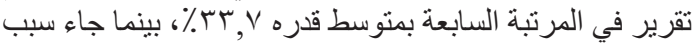

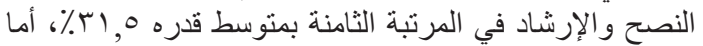

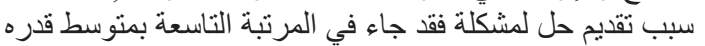

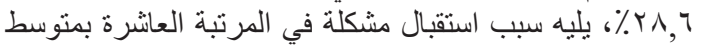

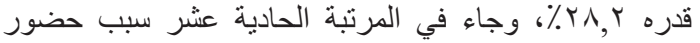

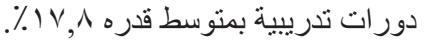

بينما تمثلت أهم أسباب الاتصال بالقادة الريفيين مرتبة

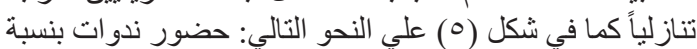

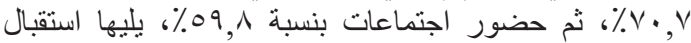

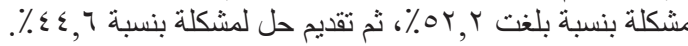
في حين جاءت أهم أسباب الاتصال بالثباب الريفي مرتبة

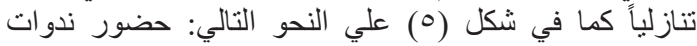

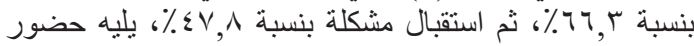

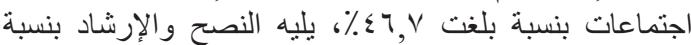

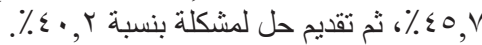

أما المر أة الريفية فقد جاءت أهم أسباب الاتصال بها مرتبة

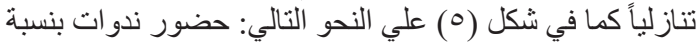

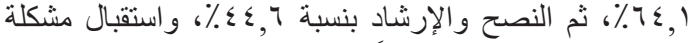

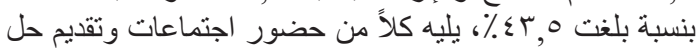

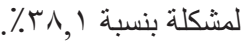

وبترتيب أسباب اتصال المبحوثين بالفئات المستهدفة تبين

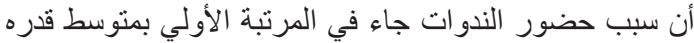

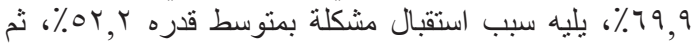

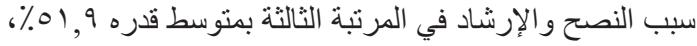

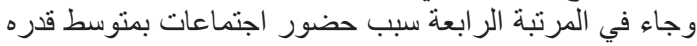

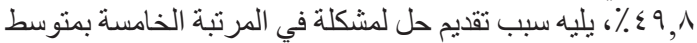

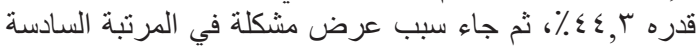

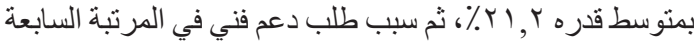

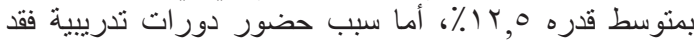

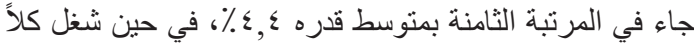

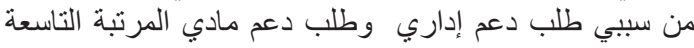

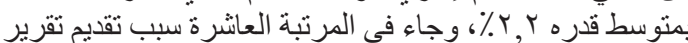

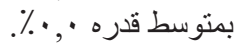

ب- سبب الاتصال بالجهات و المنظمات الرسمية: تمثلت أهم أسباب الاتصال بالتهات بزملاء ورؤساء العمل مرتبة الرسية

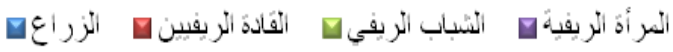

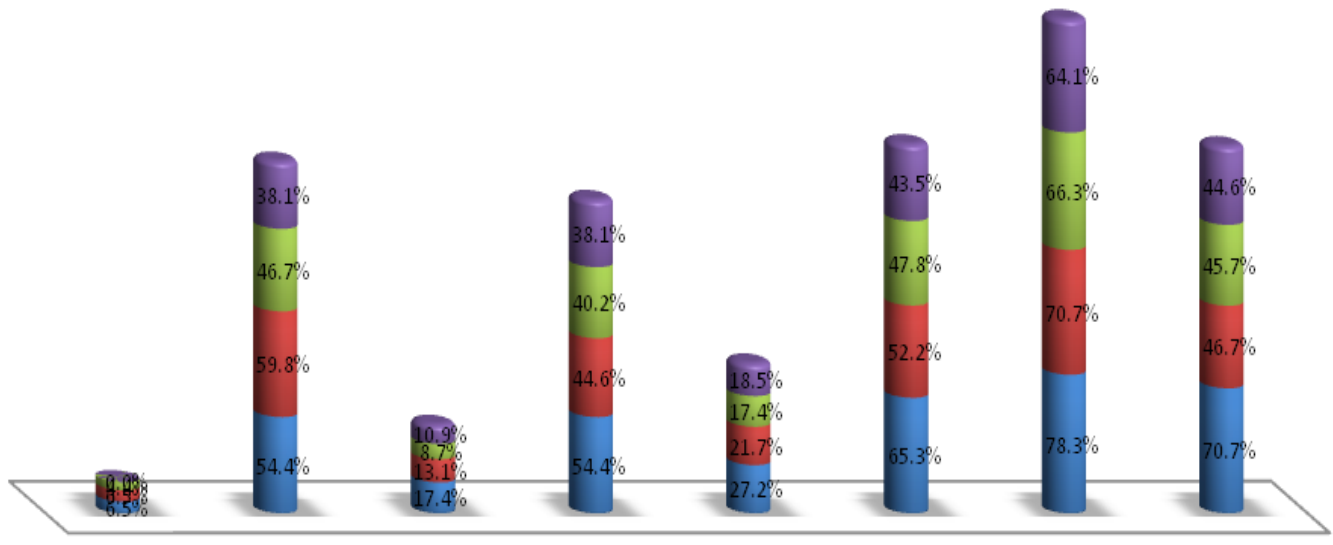

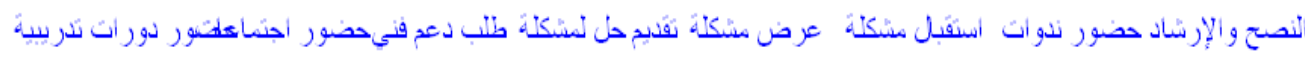

شكل •. أهم أسباب اتصال المبحوثين بالفئات المستهدفة من عملية الاتصال الإرشادي

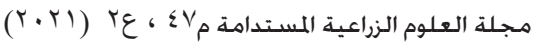


العشاء بمتوسط قدره ؟, ٪٪، يليها توقيت الاتصال ليلاً في المرتبة

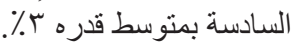

بـ ت توقيت الاتصال بالجهات و المنظمات الرسمية: تمثل أهم توقيت للاتصال بزملاء ولاء ورؤساء العمل مرتب التبات

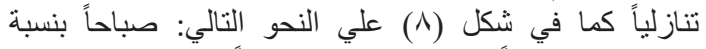

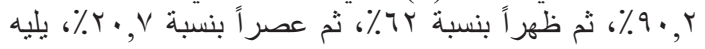

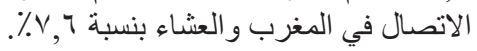

بينما تمثل أهم توقيت للاتصال بالمنظمات الاجتماعية

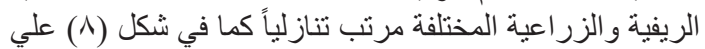

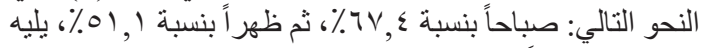

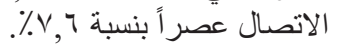

في حين جاء أهم توقيت للاتصال بالجهات البحثية (مركز

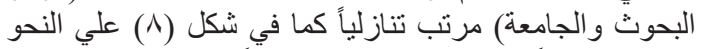

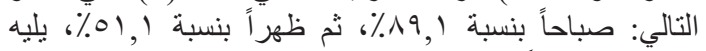

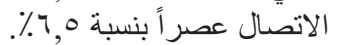

وبترتيب توقيت الاتصال بالجهات و المنظمات الرسمية

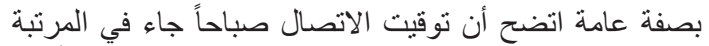

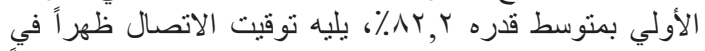

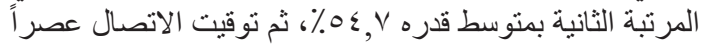

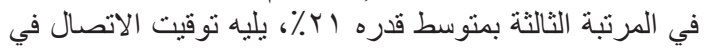

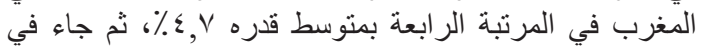

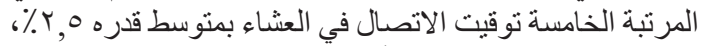

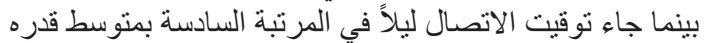
$\%, \varepsilon$
رابعاً: توقيت اتصال المبحوثين بأطر اف العلاقة الاتصالية:

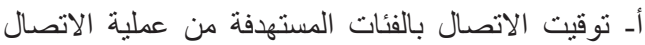

تمثل أهم توقيت للاتصال بالزر اع مرتب تناز لباً كما في شكل

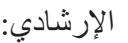

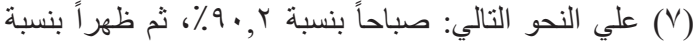

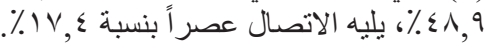

بينما تمثل أهم توقيت للاتصال بالقادة الريفيين مرتب تنازلياً

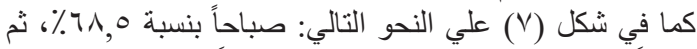

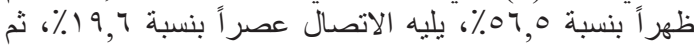

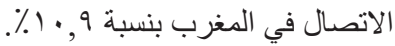

في حين جاء أهم توقيت للاتصال بالثباب الريفي مرتب

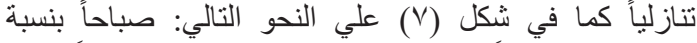

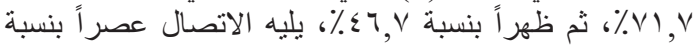

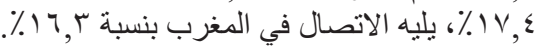

أما المرأة الريفية فقد تمثل أهم توقيت للاتصال بها مرتب

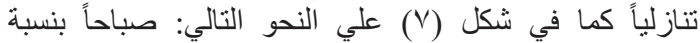

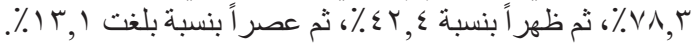

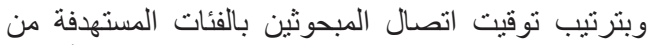

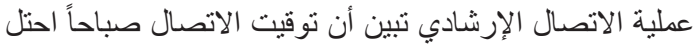

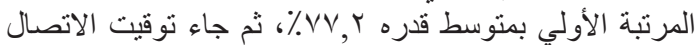

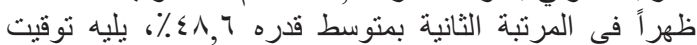

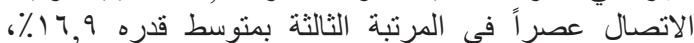

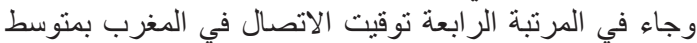

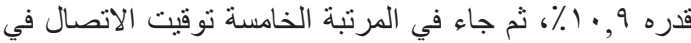

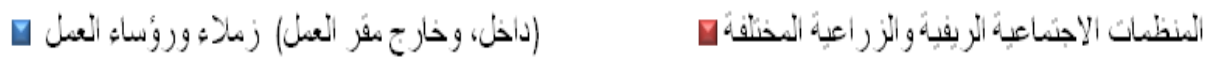

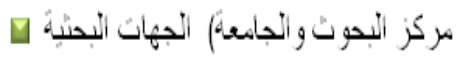

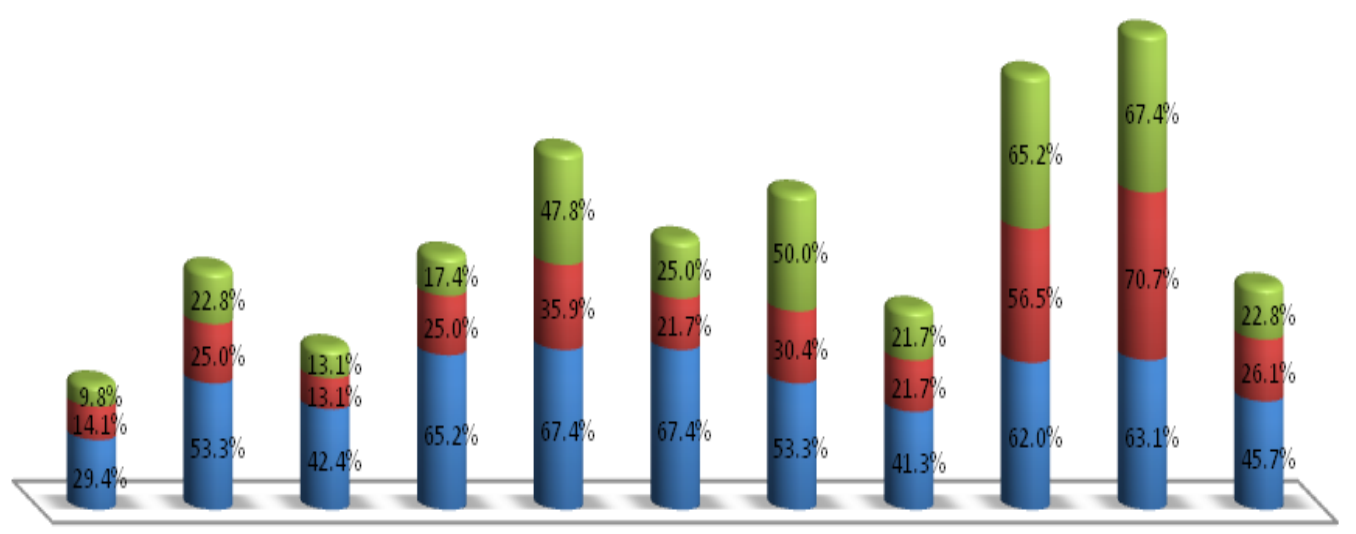

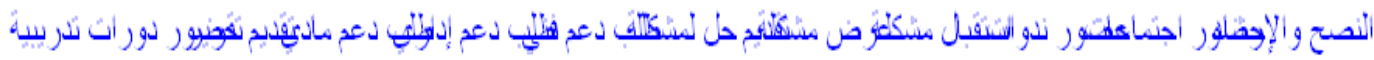

شكل 7. أهم أسباب اتصال المبحوثين بالجهات والمنظمات الرسمية 


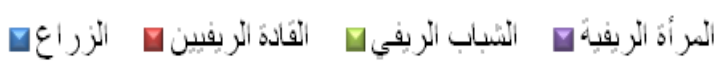

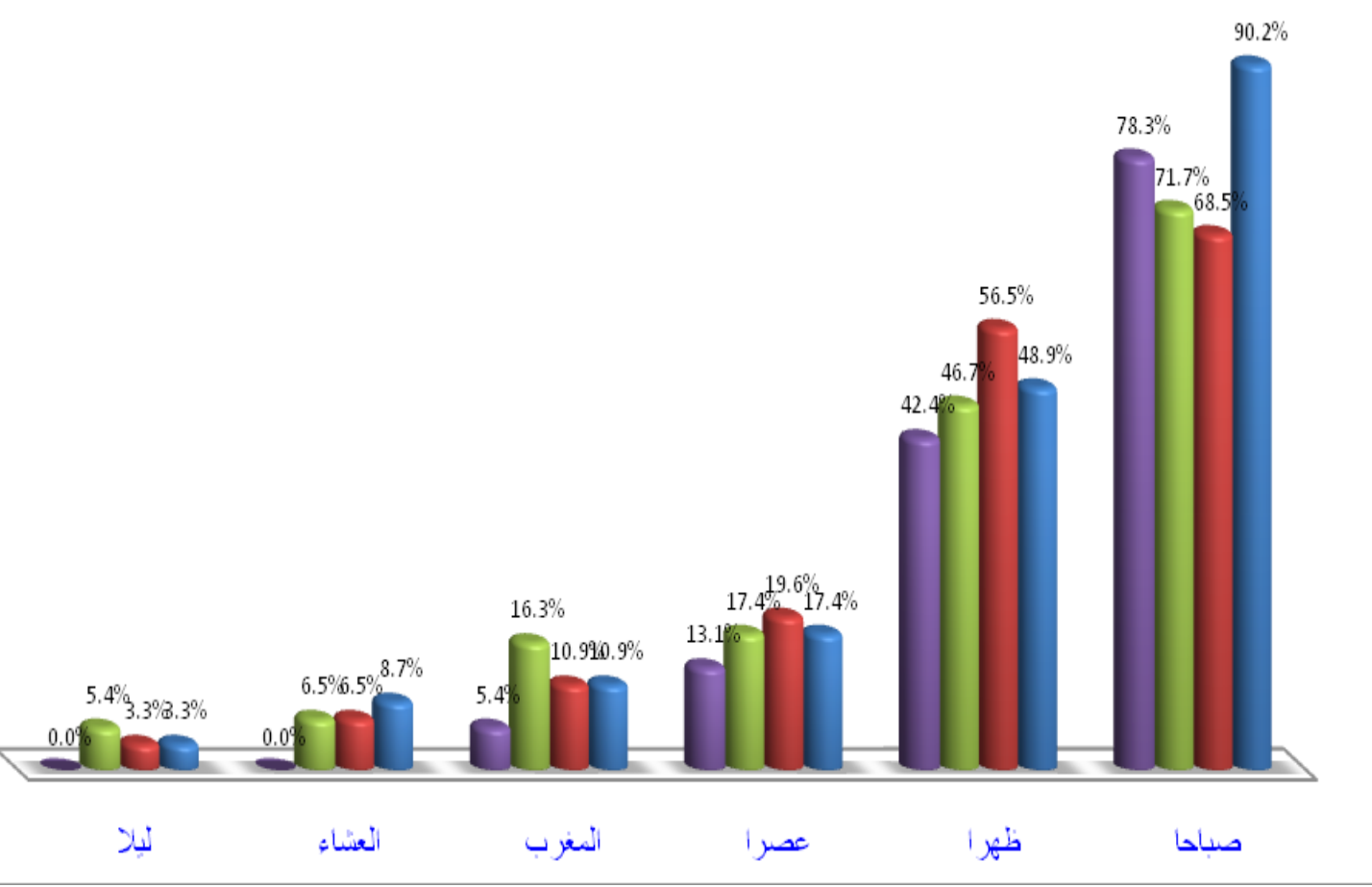

شكل V. توقيت اتصال المبحوثين بالفئات المستهافة من عملية الاتصال الإششادي

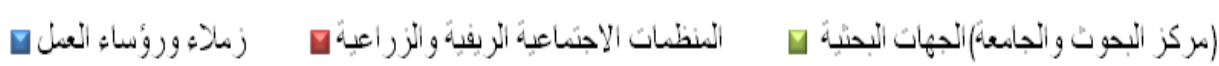

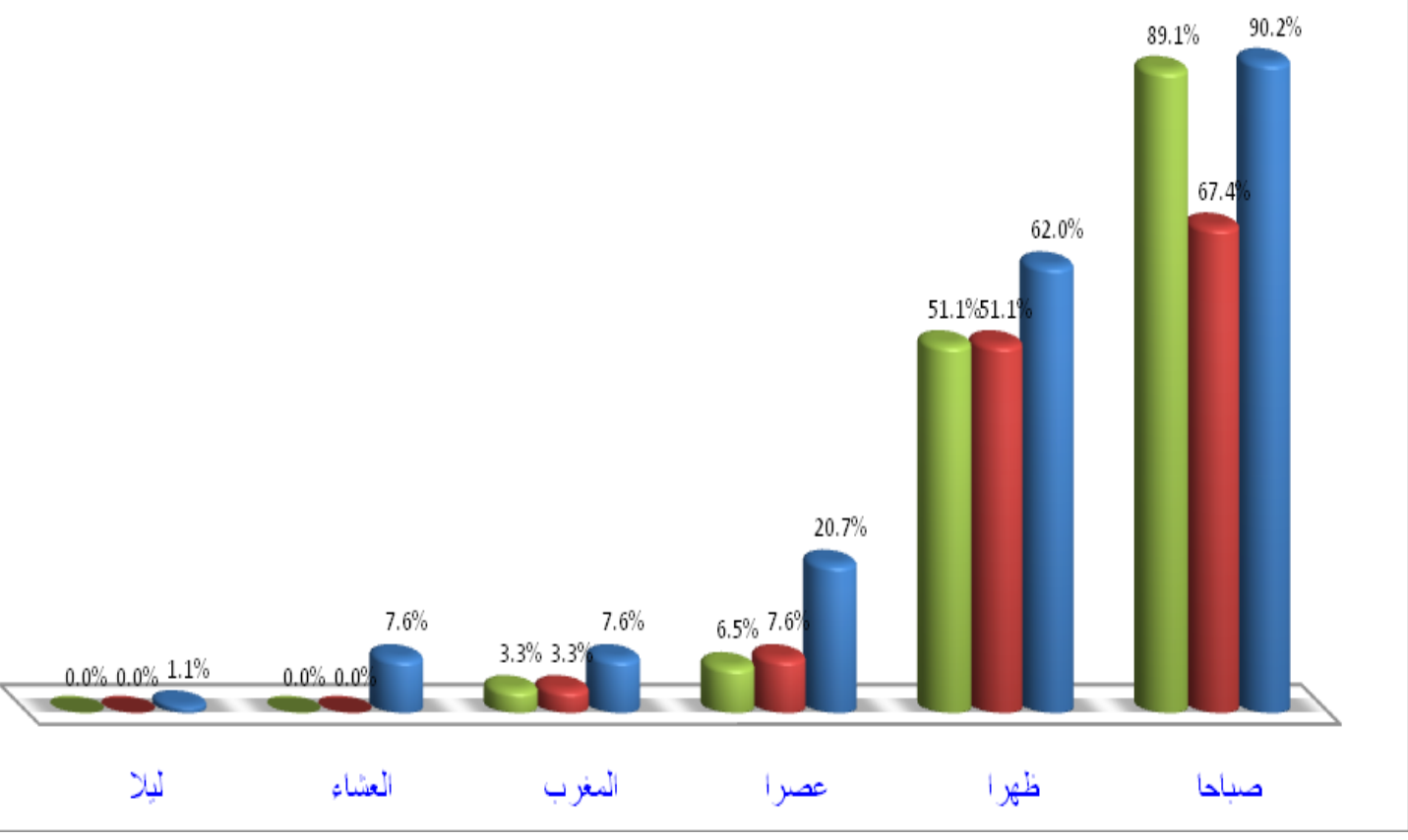

شكل ^ـ توقيت اتصال المبحوثين بالجهات والمنظمات الرسمية

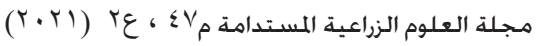




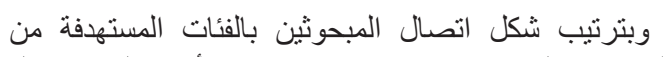

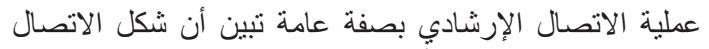

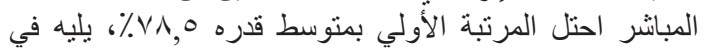

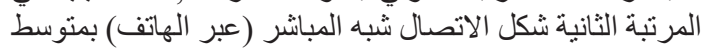

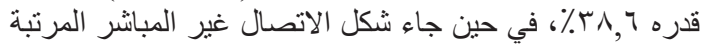

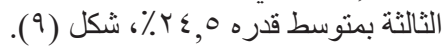

بـ شكل الاتصال بالجهات و المنظمات الرسمية:

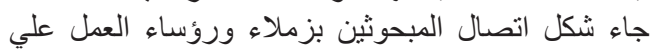

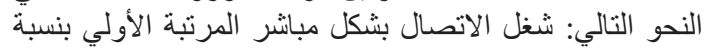

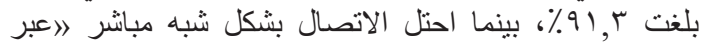

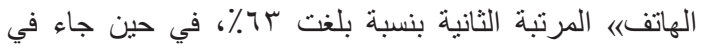

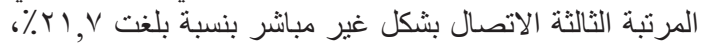

شكل (·) (1).

بينما تمثل شكل اتصال المبحوثين بالمنظمات الاجتماعية

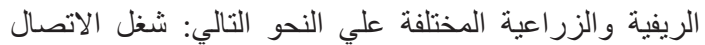

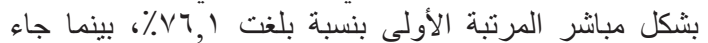

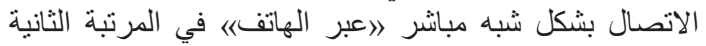

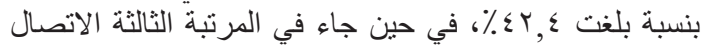

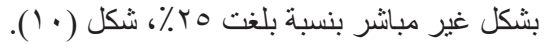

في حين تمثل شكل اتصال المبحوثين بالجهات البحثية

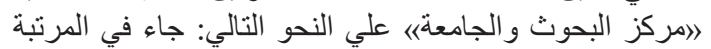

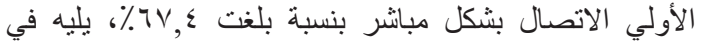

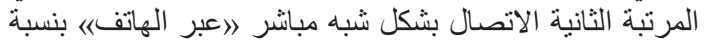

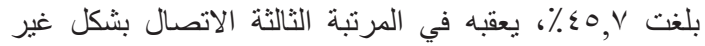

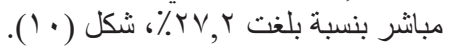

خامساً: شكل اتصال المبحوثين بأطر اف العلاقة الاتصالية:

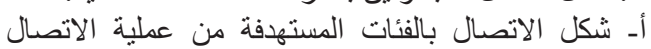

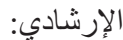

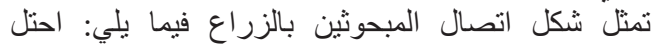

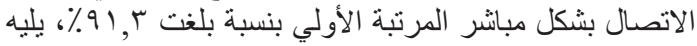

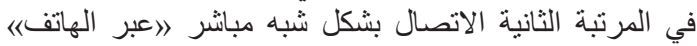

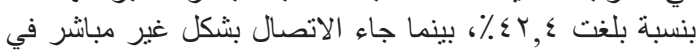

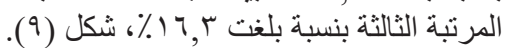

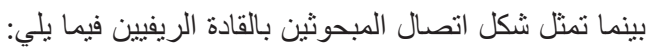

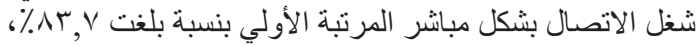

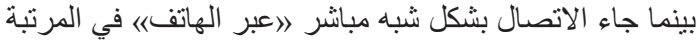

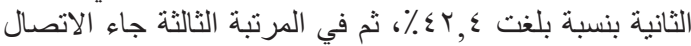

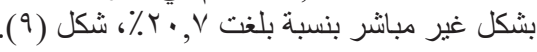

في حين جاء شكل اتصال المبحوثين بالشباب الريفي علي

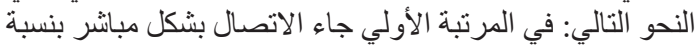

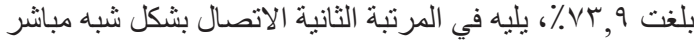

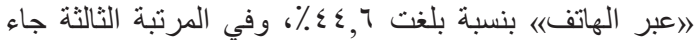

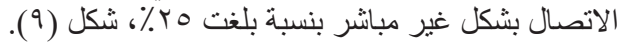

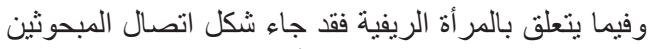

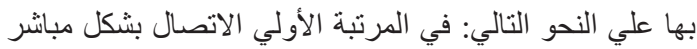

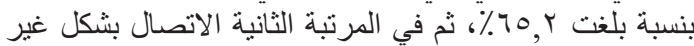

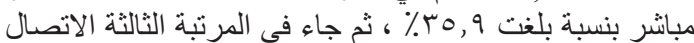

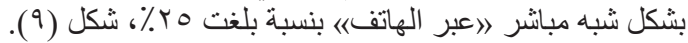

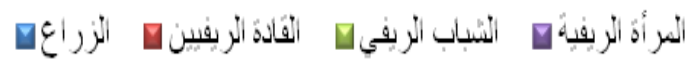

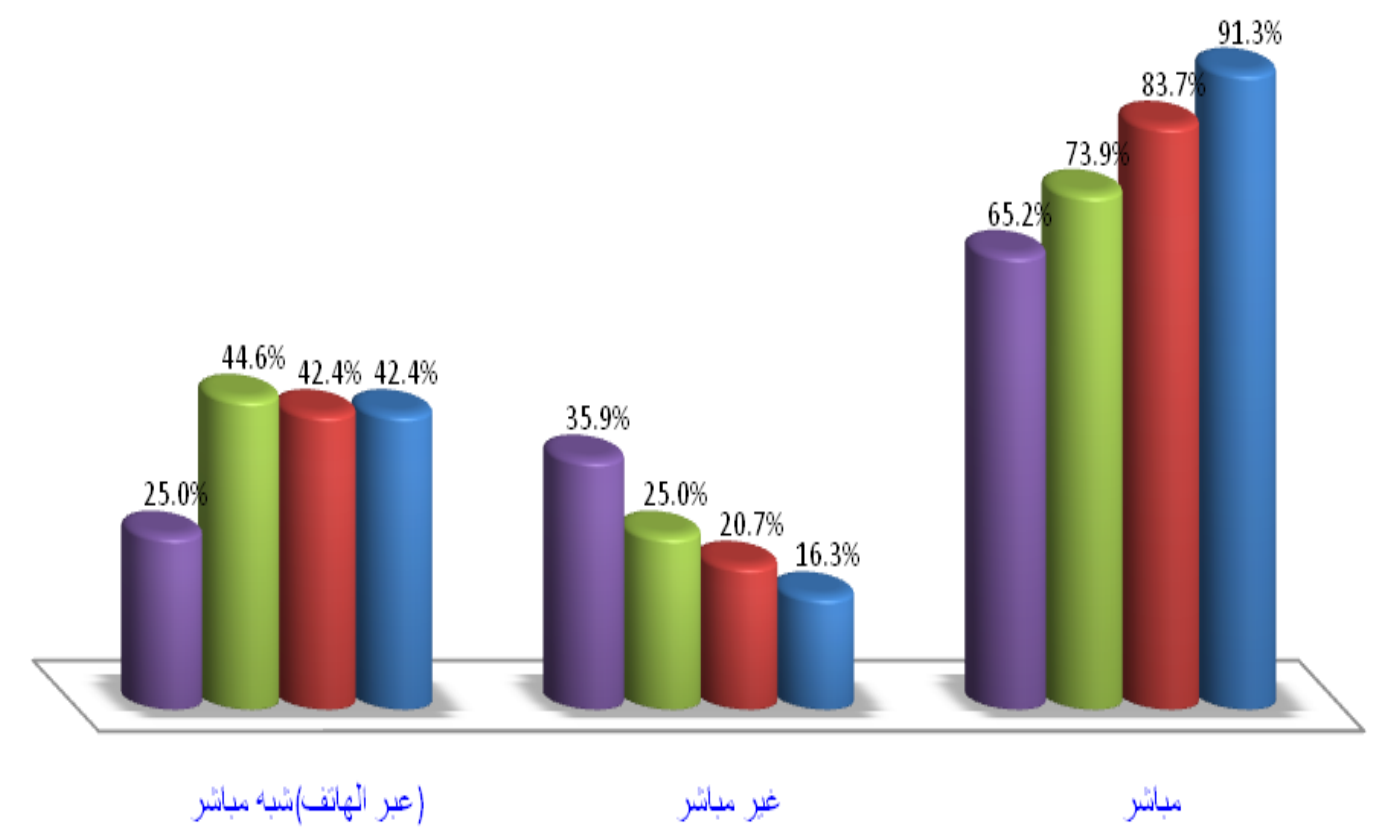

شكل 9. شكل اتصال المبحوثين بالفئات المستهذفة من عملية الاتصال الإرشادي 


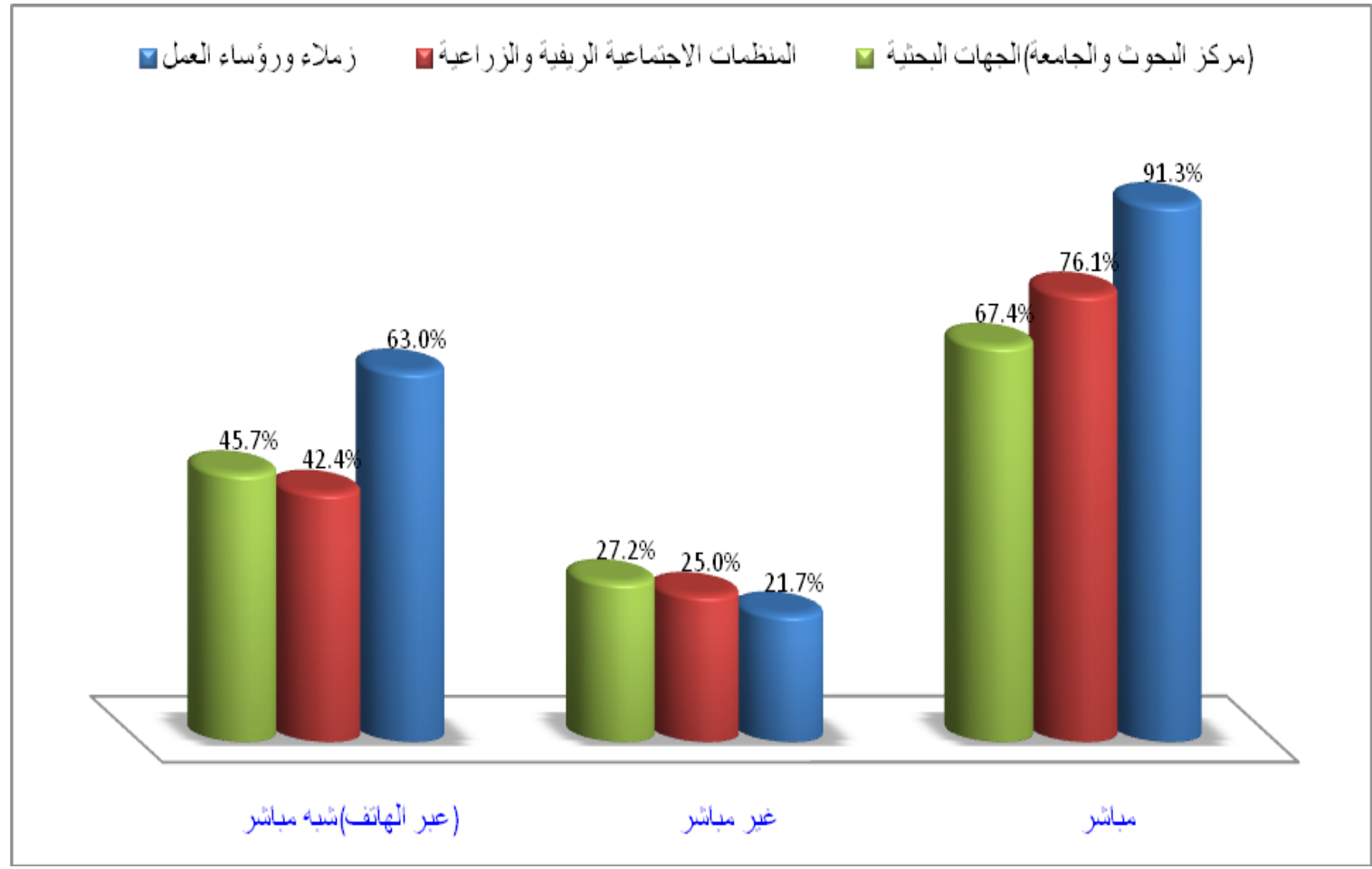

شكل ا ـ شكل اتصال المبحوثين بالجهات والمنظمات الرسمية

شاركو ا فى اعداد و نشر البحث

تضارب المصالح Conflict of interest: لا يوجد تضار مصالح بين المؤلفين المباري

المراجع - الم

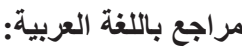

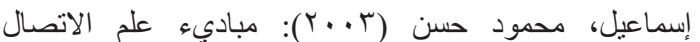

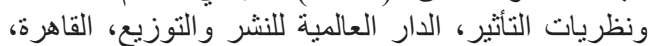

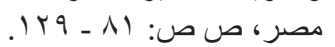

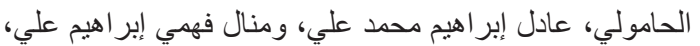

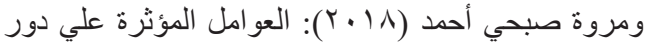

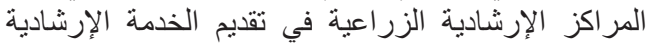

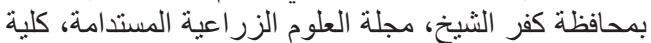

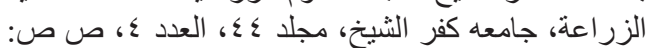

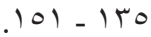

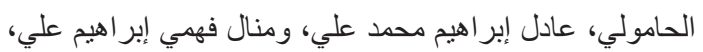

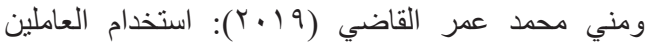

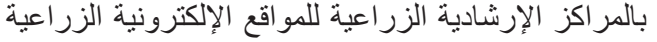

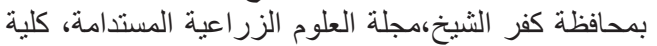

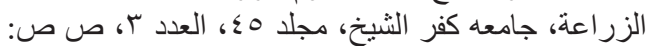

.r) - r. r

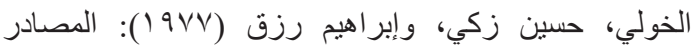

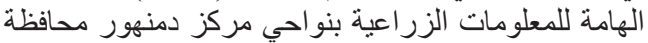

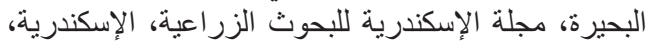

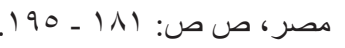

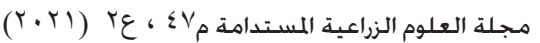

وبترتيب شكل اتصال المبحوثين بالجهات و المنظمات

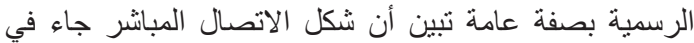

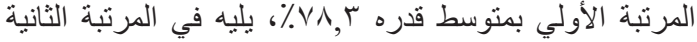

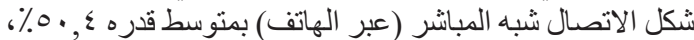

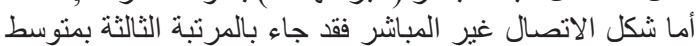

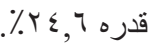

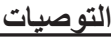

في ضوء النتائج السابقة يوصي البحث بضرورة تسهيل

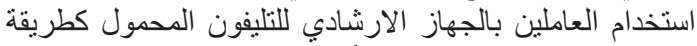

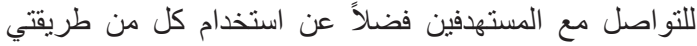

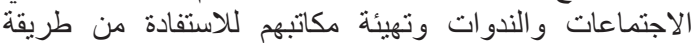

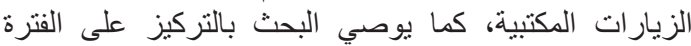

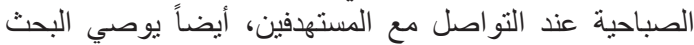

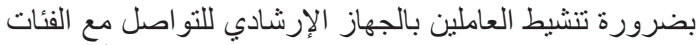

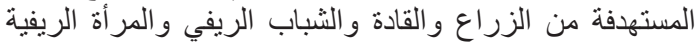

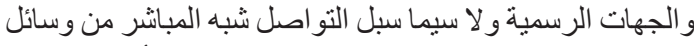

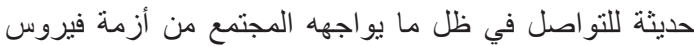

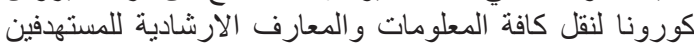

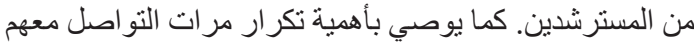

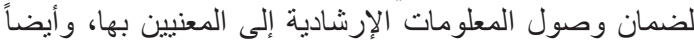

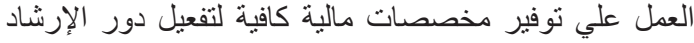

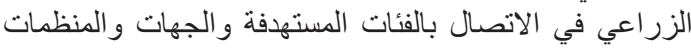
الرسمية.

التمويل Funding: لايوجد اى تمويل خارجى للار اسة مشاركة المؤلفين Author contribution: جميع المؤلفين 
الزر اعي الإلكتروني بمحافظة سو هاج، مجلة أسيوط للعلوم

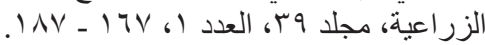

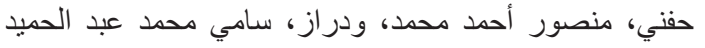

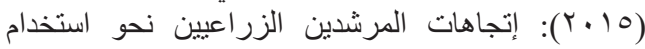

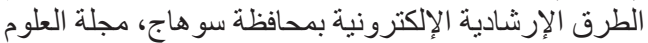

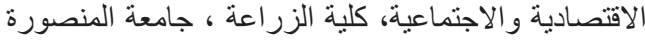

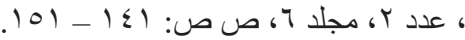

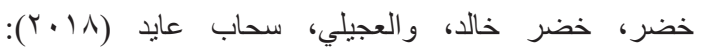

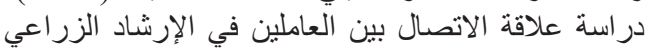

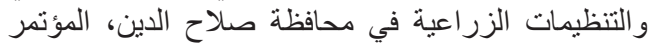

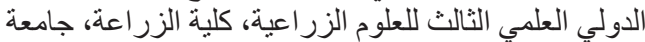
تكريت، العراق، ص ص: صل 00 ـ ـ 7.

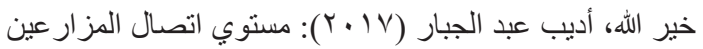

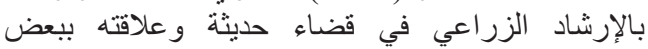

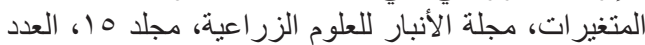

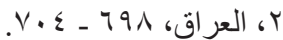

دوكاخ، دي فلوربال (99 1)): نظريات الإعلام والاتصال،

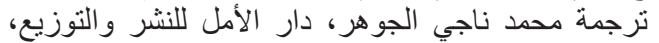

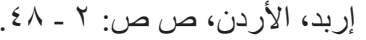

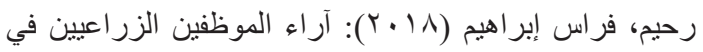

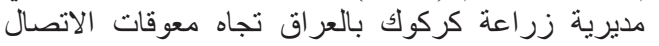

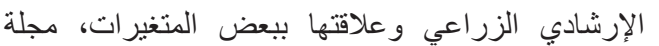

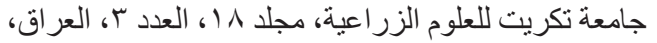

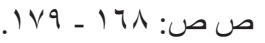

سلام، محمد شفيع ، وشكري محمد بدر ان (1990 (1)): دليل منهجية الإعزية

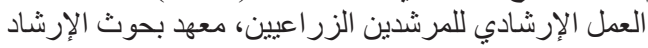

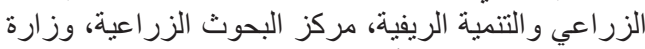

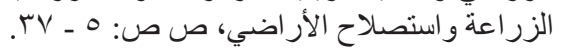
صالح، صبري مصطفي (99 (19)): المفتتح في الإرشاد

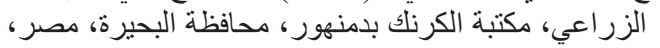

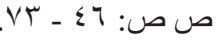

صالح، صبري مصطفي (997 ( )): الإرشاد الزراعي - طرقها

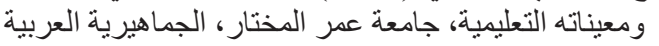

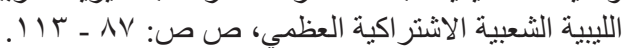

طلبة، لبلي أنور (10 • ب): طرق الاتصال الإرشادي الزراعي

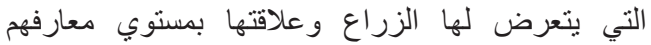

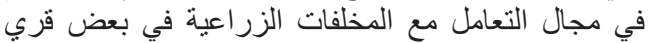
محافظتي الإسكندرية والبحيرة، مجلة الإسكندرية للتبادل

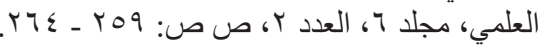
عبد المقصود، بهجت محمد (911 (1)): الإرشاد الزراعي، دار

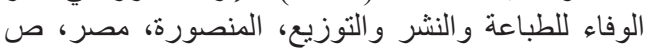

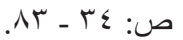

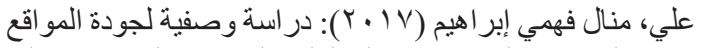

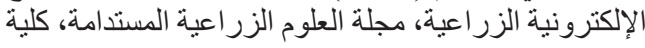

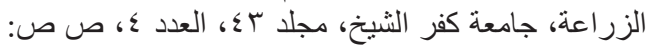
19. - 1Vo

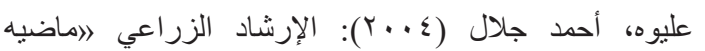

الساعدي، حبدر عباس عبد الله، وأشواق عبد الرازق البدري

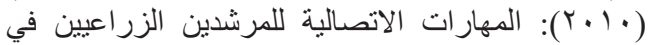

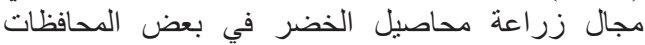

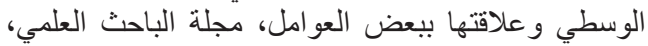

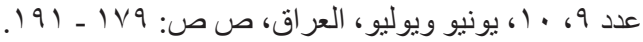

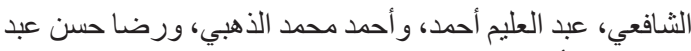

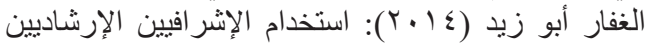

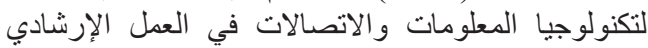

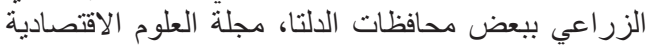

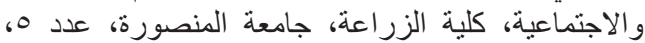

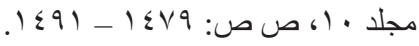

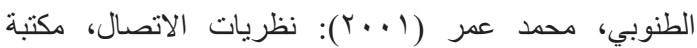

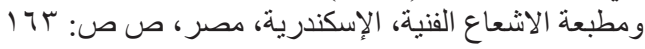
.119 -

الطنوبي، محمد عمر، والصادق سعيد عمران (1997) (19):

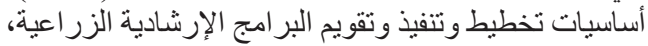

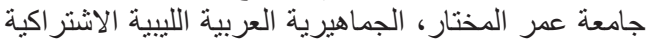

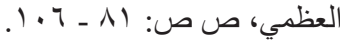

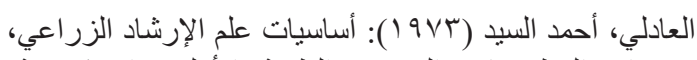

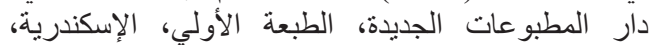

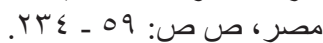

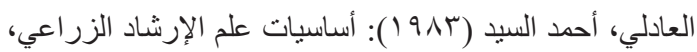

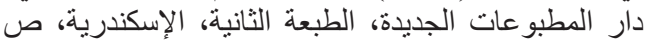

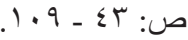

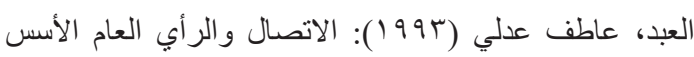

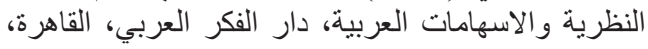

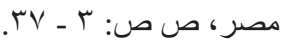

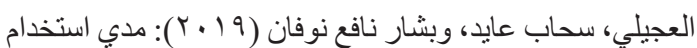

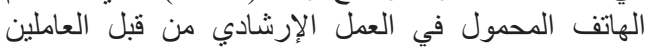

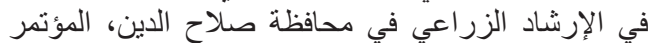

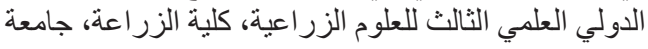

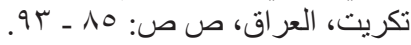

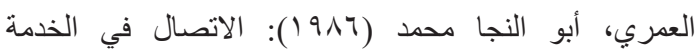

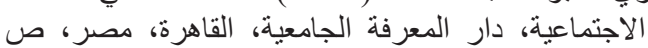

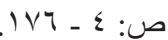

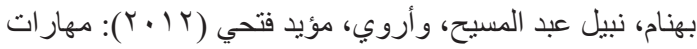

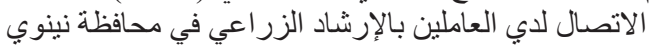

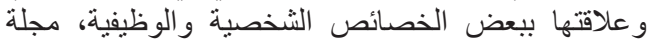
زر اعة الرافدين، عدد ب، مجلد لـع، العراق، غير مبين الصفحة.

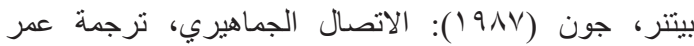

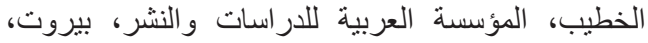

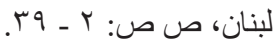

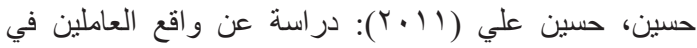

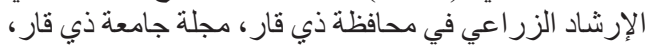

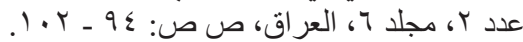

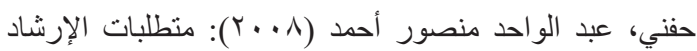

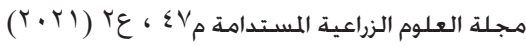




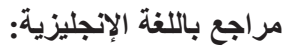

John. F. (2010): Agriculture Extension, Overseas Development Institute, London, p; 1 - 17.
وحاضره ومستقبلها《، مكتبة الأنجلو، القاهرة، مصر، ص ص

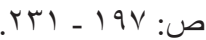

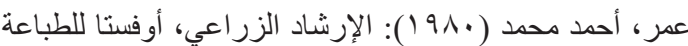

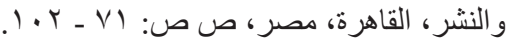

عوده، محمود (1991): أساليب الاتصال و التغيير الاجتماعي،

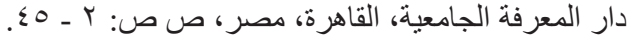

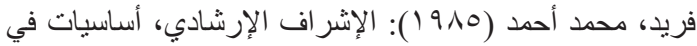

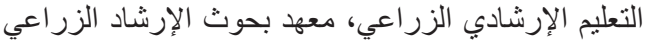

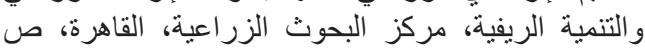
ص: 79 - 79

فواز، منصور الحكيم (11) سوسيولوجيا الإعلام الجماهيري، دار أسامة للنشر والتوزيع، عمان، الأردن،

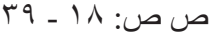

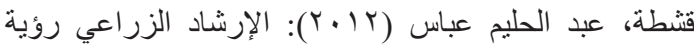

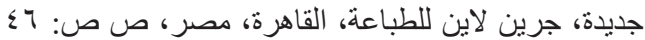
71 -

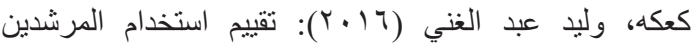

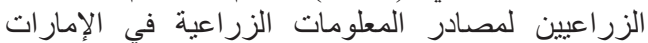
العربية المتحدة، المجلة السورية للبحوث الزراعية اعية، مجلد

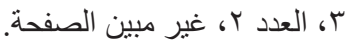

كيلسي، لنكولن دايفيد، وكانون هيرن (1990): الإرشاد

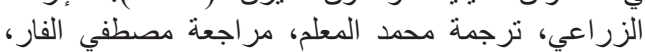

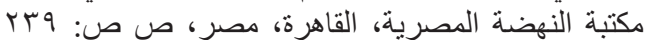
(9) -

مختار، وفيق صفوت (· • (Y): وسائل الاتصال و الإعلام وتشكيل و عي الأطفال و الثباب، دار غريب للطباعة و النشر

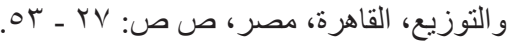

مرزبان، عبد الحليم أحمد خلف (990) (190): دليل مرجعي في

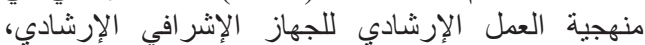

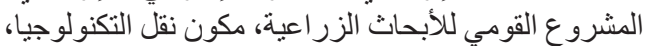

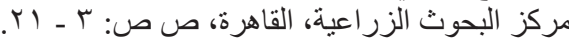
مكاوي، حسن عماد، وليلي السيد ( ( . . ( )): الاتصال ونظرياته

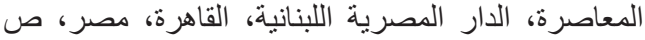
ص:

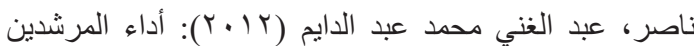

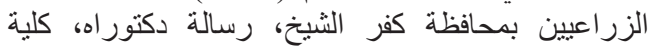

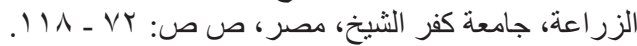

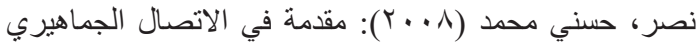

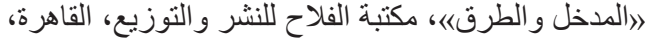

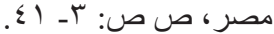

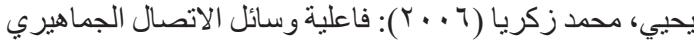

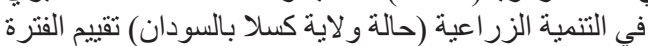

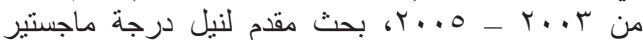

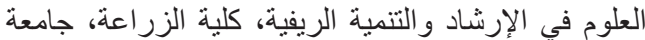

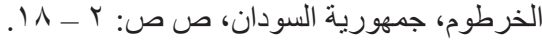




\title{
Activities of the Extension Communications for the Extension Workers at Kafr El-Sheikh Governorate
}

\author{
Adel I. Elhamoly ${ }^{1}$, Ahmad M. Abdallah ${ }^{1}$,Abdaleem S. Elshafay andEzzat ${ }^{2}$ M. \\ Megahed $^{1}$ \\ ${ }^{1}$ Dept. of Agric. Economics, Facultyof Agric., Kafrelsheikh University \\ ${ }^{2}$ Agric. Research Center.
}

$\mathbf{T}$

HE paper mainly aimed to identify the activities of the extension communications for extension workers at Kafr El-Sheikh governorate. The research data were collected from all the respondents by the personal \& telephone questionnaire and E-mail. It was analyzed by using several statistical tools as: percentage, frequencies, means, and, weight means. The most important results included the most extension communication methods uses for target groups such as farmers, rural leaders, rural youth and rural women were: Informational symposium about $89.1 \%$, extension posters by $74.8 \%$, then mobile phone by $56.5 \%$, office visits by $54.4 \%$., and for the official authorities such as colleagues \& heads of work, rural \& agricultural social organizations, and research centers (Research Center and the University) were: mobile phone by $75 \%$, then office visits at $65.2 \%$, extension meetings by $56.5 \%$. It was found that the weekly communication was first place with an average of $40.8 \%$, followed by the monthly communication by $31.9 \%$, then the daily communication by $31.8 \%$ and it was found that the timing of the morning communication came first then at noon by $77.2 \%$, and $48.6 \%$ respectively.

Keywords: Farmers, communication activities, leaders, rural women, organizations, youth, Methods, extension workers. 